\title{
Landscape Preferences and Patterns of Residential Development
}

\author{
Matthew A. Turner \\ Department of Economics \\ University of Toronto \\ 150 St. George Street \\ Toronto, Canada M5S 3G7 \\ mturner@chass.utoronto.ca
}

August 2004

Forthcoming Journal of Urban Economics

\begin{abstract}
I analyze a model of residential location choice where people derive utility from their proximity to open space. When people have such landscape preferences then (1), equilibrium residential development is mixed with undeveloped land (2), equilibrium land price gradients depend sensitively on how land markets are organized, are not generally monotonic, and may or may not reflect the value of open-space, and (3), dynamic equilibria generally have the property that more remote areas are developed before more central areas. Finally, when compared to optimal development, equilibrium development houses too many residents, too close together, and remote areas are developed too soon. These results imply that equilibrium development may not be sprawling enough and that policies to encourage infill development are not welfare improving.
\end{abstract}

KEYWORDS: Sprawl, Landscape preferences. J.E.L.: R2, H0. 


\section{Introduction}

The importance of open space in developed landscapes is confirmed by a drive through almost any new suburb and by recent empirical work. ${ }^{1}$ For example, J. Geoghegan [1] finds that $47 \%$ of the land within $1600 \mathrm{~m}$ of an average house in suburban Maryland is undeveloped, ${ }^{2}$ while M. Burchfield, H. G. Overman, D. Puga and M. A. Turner [2] find that new residential development strongly favors areas where old development covers only a small fraction of the surrounding square kilometer. In addition, casual empiricism and a small empirical literature indicate that people care a great deal about the characteristics of their residential landscape. In particular, they care about the amount and quality of nearby open space. Given this taste for open space and the prevalence of open space in our residential landscapes, it is important to assess the implications of landscape preferences for the development of equilibrium and optimal cities.

The preservation and development of open space are also central issues in the ongoing debate about urban sprawl. For example, the American Planning Association [3], the American Institute of Architects [4], the Urban Land Institute (D. J. O'Neill [5]), and the Sierra club [6], all advocate 'infill development', i.e., the development of vacant land in the interior of cities, as an alternative to more sprawling cities. Interest in land use policy also extends outside of these interest groups: between 1998 and 2001, more than 500 measures raising public revenues for land acquisition were approved by voters across the United States (Trust for Public Land [7]), and a number of cities have created 'greenbelts' around their periphery where development is forbidden. It is important to investigate the implications that these different land use policies have for the development of cities and the welfare of their inhabitants. Given the importance of landscape preferences, it makes sense to conduct this investigation in a theoretical framework which allows for such preferences.

The existing literature, however, provides little insight into the role of landscape preferences as a determinant of residential location choice, and less about the optimal choice of open space policy. With few exceptions, existing theoretical models of urban spatial structure do not allow for the possibility that people care about the residential landscape. This paper begins the work of understanding the role of landscape preferences as a determinant of patterns of residential location. Specifically, I consider a model of residential location choice in which people have a taste for proximity to open space.

\section{Related literature}

The principal innovation of the model developed here is that it allows people to derive utility from open space near their residential location. While common sense and casual empiricism alone make a strong case for this, there is also an empirical literature devoted to the measurement of

\footnotetext{
${ }^{1}$ I am grateful for the support of SSHRC and the National Fellows program at the Hoover Institution. I am also grateful to Jan Breuckner, Vern Henderson, Janet Kohlhase, Diego Puga, Elena Safirovia, Will Strange, and seminar participants at SUNY Buffalo and the University of Minnesota for helpful comments.

${ }^{2}$ Undeveloped land here falls into two categories; 'Developable open space' which is made up of agricultural cropland, pasture and forest, and 'Permanent open space', which is made up of parks and land subject to conservation easements.
} 
such landscape preferences. ${ }^{3}$ This literature finds strong evidence that people have a taste for open space near their houses.

A second literature relevant to this analysis examines the role of positive production externalities in the formation of cities. This literature is interested in understanding the implications of 'knowledge spillovers' which allow firms working in close proximity to work more efficiently than firms which are isolated from each other. An analysis of knowledge spillovers is similar to an analysis of landscape preferences. In the case of knowledge spillovers, agents impose positive spillovers on their neighbors by locating nearby. In the case where agents have a taste for open space, agents impose negative externalities on their neighbors by locating nearby and occupying valuable open space.

Often the literature on knowledge spillovers treats production externalities as being constant within an agglomeration of production activity, e.g., J. V. Henderson and A. Mitra [14], and thus provides little basis for thinking about the fine details of spatial structure within neighborhoods. There are exceptions to this, however. M. Fujita and H. Ogawa [15], R. W. Helsley [16], M. Berliant, S. Peng and P. Wang [17], and, R. E. Lucas, Jr. and E. Rossi-Hansberg [18], analyze cities in which firms have tastes about the number and proximity of nearby firms. For example, firms in $\mathrm{R}$. E. Lucas, Jr. and E. Rossi-Hansberg [18] become more productive as the amount of production activity in their proximity increases, but the impact of a unit increase in nearby production activity decays exponentially with its distance from the target firm. Unlike the canonical monocentric city model where firms care only about land prices, in models with neighborhood externalities, firms care about the location of all other firms and land prices when making location choices. This complicates the analysis of these models tremendously.

A third related literature provides other possible explanations of open space within city boundaries. In particular, this literature suggests three mechanisms that may give rise to open space in the residential landscape. First, when investment decisions are irreversible it may be efficient to postpone development of certain parcels so that they can be developed in a way that better suits future needs (J. C. Ohls and D. Pines [19], M. Fujita [20], D. E. Mills [21], J. K. Brueckner and B. Vonrabenau [22], G. K. Turnbull [23], R. M. Braid [24, 25], M. Fujita [26]). Second, equilibrium leapfrogging may also result from irreversible housing investment decisions when building takes time and uncertainty over land rents increases with distance from the city center (A. Bar-Ilan and W. C. Strange [27]). Each of these two mechanisms is able to generate open space as part of a pattern of residential development. Third, exclusionary municipal zoning may lead to undeveloped land as people decline to locate in highly regulated jurisdictions in favor of their less regulated neighbors (K. T. Rosen and L. Katz [28], L. Katz and K. T. Rosen [29]).

Given that results in J. Geoghegan [1] and M. Burchfield et al. [2] indicate that residential landscapes often contain a high proportion of undeveloped land, it is clearly desirable to have an arsenal of explanations with which to explain it, and each of the three explanations given above is likely to contribute to the observed levels of open space. However, the model developed below

\footnotetext{
${ }^{3}$ Examples include, S. D. Shultz and D. A. King [8], M. Kahn [9], J. Geoghegan, L. A. Wainger and N. E. Bockstael [10], E. G. Irwin and N. E. Bockstael [11], E. G. Irwin [12] , and G. Acharya and L. Lewis Bennett [13]. See J. Geoghegan [1] for a more extensive bibliography.
} 
is new to the literature and a back of the envelope calculation in section 6 suggests that a taste for open space may, by itself, be able to explain a large share of observed open space.

With this said, there are a small number of theoretical investigations into the role that landscape preferences play in the development of cities. R. Walsh [30] considers a Tiebout type model in which people have preferences over the characteristics of the neighborhood landscape, the amount of open space in particular. While this is an interesting analysis, since the Tiebout framework does not allow an analysis of location choices at a scale smaller than the 'neighborhood', it is not well suited to the analysis of the micro-structure of development that is undertaken here. L. Tajibaeva, R. Haight and S. Polasky [31] consider a similar model. J. K. Brueckner [32] analyzes a city where people have a taste for open space at the edge of a monocentric city. While this analysis is clearly complementary to the present endeavor, the tastes under consideration are quite different. Perhaps the closest competitor to this paper is W. C. Strange [33], which considers a similar spatial model but does not model a land market. Finally, J. J. Wu and A. J. Plantinga [34] consider city formation when people have a taste for proximity to exogenously located parks. While their analysis is also interested in the role of open space in city formation, it does not consider the possibility that people impose external costs on each other by their choice of location, and so has little relationship to the current inquiry.

\section{Static model}

I would ultimately like to understand policies which govern the preservation and development of open space in residential landscapes. To accomplish this, I consider a model of the development that arises in response to an increased demand for housing at the edge of a city.

The first step is to specify the cause of the increased demand for housing. The simplest option is to require that a group of immigrants choose to locate in the city for reasons exogenous to the model. Such a 'closed city' model is consistent with increases in housing demand due to population growth in a city where there is little opportunity for migration. A second possibility is to suppose that there is a large pool of potential immigrants who must choose a residential location, and that the city of interest has just experienced an exogenous shock that makes it attractive to these immigrants. Such an 'open city' model is consistent with an economy where most population growth is due to immigration and there is mobility across cities.

Both open and closed city models serve the purpose of creating a wave of immigrants interested in locating in the subject city. However, given North America's high rates of immigration and mobility ( M. Burchfield et al. [2]), the open city model seems the more accurate description of the region's development process. Since open city models are also marginally easier to analyze, the analysis that follows is conducted in the context of an open city model. I have duplicated many of the results that follow in the context of a closed city model and there are few interesting changes in the results. Note that in both open and closed city models population increase is assumed to occur in discrete waves rather than continuously. While this may be defensible as a stylized description of the process by which people arrive in a city, the assumption is made chiefly to simplify the model. 
To begin, consider a city that is in equilibrium until just before the analysis begins, at which time local wages increase exogenously. Migration to the city occurs in response to this increase in the local wage, and immigrants have the choice of a location in the city under study, or in some other city. We consider new development that occurs at the city's edge to house new arrivals.

Let $Y=\{1, \ldots, m\}$ denote the set of available locations, and $y \in Y$ a particular location. Implicitly $y=0$ is the old city limit, the most extreme developed location in the pre-existing city, while each subsequent location is one unit distance further from this old city limit. All locations to the left of zero are assumed to be unavailable. ${ }^{4}$

The land at each location is owned by a landlord, each of whom owns exactly one location. Index landlords by $y \in Y$ where a landlord's name also gives the location of his parcel. Let the set of potential immigrants be $N=\{1, \ldots, n\}$ and let $i$ index this set. Potential immigrants must choose between a location in the area described by $Y$, or another location $\theta$, implicitly some other city. Denote immigrant $i$ 's choice of location by $y_{i} \in Y \bigcup\{\theta\}$. Conversely, let $i(y)$ denote the immigrant(s) occupying location $y$, with $i(y)=\phi$ if $y$ is unoccupied. Throughout the paper 'int $(y)^{\prime}$ refers to the largest integer that is less than or equal to $y$. Let $X_{N}$ denote a location profile, a set of occupied locations in $Y$ after all prospective immigrants have moved. If more than one immigrant chooses the same location $y$, then the location profile $X_{N}$ will contain multiple copies of $y$. If all immigrants choose $\theta$ then $X_{N}$ is empty. Finally, let $X_{-i}$ denote a list of the location choices of all immigrants but $i$, i.e., $X_{-i}=X_{N} / y_{i}$.

Note that the model implicitly restricts all agents to choose lots of the same fixed size. This assumption is maintained during most of the analysis in the interests of tractability, but is relaxed in section 5 .

Each landlord chooses, $p_{y}$, a non-negative price for his land. If no immigrant chooses a landlord's location then the landlord receives the prevailing price in the best non-residential land use. To lighten notation, normalize this price to zero. Let $P=\left\{p_{1}, \ldots, p_{m}\right\}$ denote a choice of price for all landlords, and $P_{-y}=P / p_{y}$, a choice of price for all landlords but $y$.

All immigrants pay whatever price is associated with their choice of location and all immigrants commute into the old city to work for wage $w$. The unit cost of commuting is the numeraire. Immigrants receive a utility bonus $\delta$ if and only if both locations adjacent to the one they occupy are vacant. Immigrants are averse to sharing a location, and if two immigrants occupy the same location they receive a large negative payoff. Tenants who choose location $\theta$ get reservation utility level $u_{\theta}$. Summing up,

$$
u_{i}\left(y_{i}, p_{y_{i}}, X_{-i}\right)= \begin{cases}w-y_{i}-p_{y_{i}}+\delta & \text { if } y_{i} \text { is vacant and has no occupied neighbors } \\ w-y_{i}-p_{y_{i}} & \text { if } y_{i} \text { is vacant and has at least one occupied neighbor } \\ -\infty & \text { if } y_{i} \text { is occupied by another immigrant } \\ u_{\theta} & \text { if } y_{i}=\theta .\end{cases}
$$

This specification of preferences requires that people care only about lots adjacent to their own. Such extreme simplicity is desirable for the clarity and tractability it brings to the analysis. The

\footnotetext{
${ }^{4}$ Later results will show that the absence of available locations to the left of zero is not obviously consistent with the old city having been in equilibrium. The assumption is maintained in order to simplify the analysis.
} 


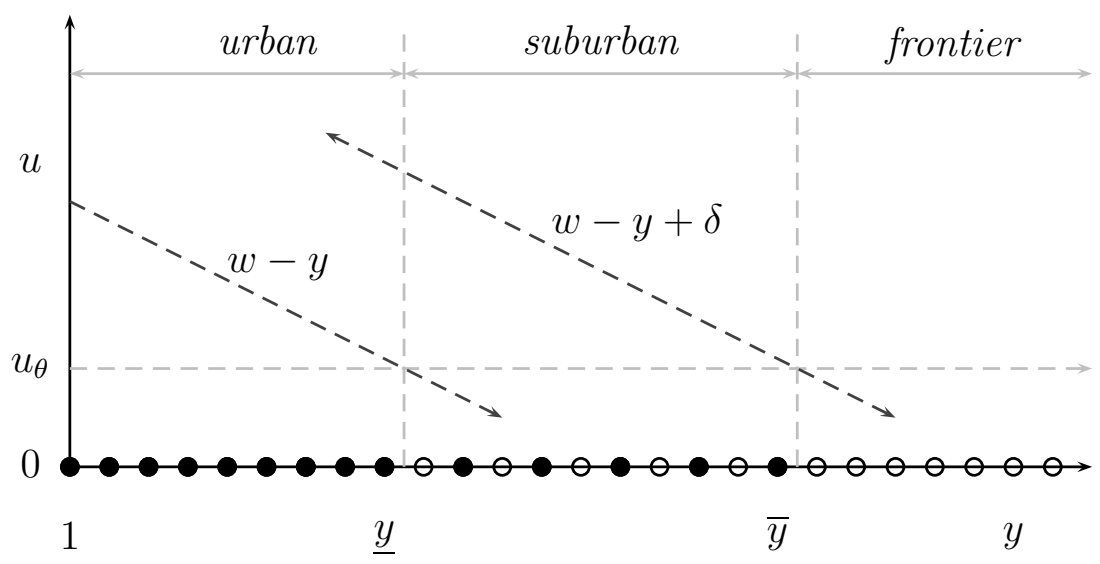

Figure 1. A characteristic equilibrium location profile for the simultaneous arrival game with land transactions at opportunity cost. All locations satisfying $w-y \geq u_{\theta}$ are occupied. Alternate spaces are occupied in the region where $y$ satisfies $w-y<u_{\theta}<w-y+\delta$. Locations are not occupied if $w-y+\delta<u_{\theta}$.

price of this simplicity is that these preferences cannot be regarded as being literally true. Instead, they should be regarded as a stylization of the fact that people have a taste for 'nearby' open space.

While the model is presented as describing individual location choices, there does not appear to be any obstacle to regarding it as a model of subdevelopment location. In this case the 'immigrants' are developers, lots are subdevelopments, and the open space premium measures the benefits of having an open field adjacent to a subdevelopment. Arguably, this interpretation of the model conforms more closely to observation than does the one adopted throughout the exposition. ${ }^{5}$

It is clearly of interest to analyze richer and more general preferences over landscapes. However the empirical literature, as yet, provides little basis for refining the statement that "people like to have open space nearby". ${ }^{6}$ Given this, I make use of the current simple specification to improve tractability.

\section{A. Simultaneous arrival game with land transactions at opportunity cost}

To complete the specification of the model it remains to describe the timing of moves and the operation of the land market. I begin with the case where landlords are constrained to rent land at its opportunity cost and immigrants move simultaneously. While these assumptions are unrealistic, they provide the simplest possible environment in which to illustrate the incentives that drive behavior in more complex models. Surprisingly, the equilibrium location profile in all of the games considered here is exactly the same as the one that emerges in this game without a land market. Thus, besides its pedagogic value, the analysis of this simple game demonstrates the robustness of the location patterns which emerge in this class of models.

\footnotetext{
${ }^{5}$ I am grateful to an anonymous referee for suggesting this interpretation of the model.

${ }^{6}$ For example, J. Geoghegan et al. [10] find that open space within 100m of a house increases its value, but all else equal housing prices decrease with open space between $200 \mathrm{~m}$ and $1000 \mathrm{~m}$ from a house. G. Acharya and L. Lewis Bennett [13], on the other hand, find that open space within one quarter mile and one mile of a house has about the same effect on housing prices.
} 
Consider the pure strategy Nash equilibria of the game in which all landlords are restricted to choose $p_{y}=0$ and all immigrants simultaneously choose a location from the set $Y \bigcup\{\theta\}$. Thus, a strategy for an immigrant is a mapping $S_{i}: X_{-i} \mapsto Y \bigcup\{\theta\}$, and an equilibrium is a choice of strategy for each immigrant, $S_{N}^{*}=\left(S_{1}^{*}, \ldots, S_{n}^{*}\right)$. Let $X_{N}^{*}$ denote a Nash equilibrium profile of location choices.

For any given profile of location choices, $X_{N}$, let $\bar{y}$ denote the most extreme occupied space and $\underline{y}$ denote the most extreme occupied space with at least one occupied neighbor. Theorem 1 provides a complete characterization of the equilibria of this game. Like the theorems that follow, theorem 1 assumes that the set of potential immigrants is large enough that not all of them will be accommodated by the city under study. This assumption allows me to avoid discussing trivial equilibria with small numbers of immigrants. Theorem 1 also makes the simplifying assumption that neither $w-u_{\theta}$ nor $w-u_{\theta}+\delta$ are integers. The reason for this assumption is discussed below. Proofs are presented in an appendix.

Theorem 1 Assume that neither $w-u_{\theta}$ nor $w-u_{\theta}+\delta$ are integers and that $n>w-u_{\theta}+\delta$. Then $X_{N}^{*}$ is a Nash equilibrium location profile if and only if the following conditions hold:

1. All locations $y \leq \underline{y}$ are occupied, where $\underline{y}=\operatorname{int}\left(w-u_{\theta}\right)$.

2. All spaces $y>\bar{y}$ are vacant, where $\bar{y}=\operatorname{int}\left(w-u_{\theta}+\delta\right)$.

3. Alternate spaces are occupied in the region $\{\underline{y}+1, \ldots, \bar{y}\}$, with $\underline{y}+1$ vacant.

Theorem 1 establishes that the simultaneous arrival game has a unique equilibrium outcome of the form illustrated in figure 1. An equilibrium development profile consists of three regions. An urban region near the old city limit which is solidly occupied, a more extreme suburban region where only alternate spaces are occupied, and an unoccupied frontier. The intuition for this result follows.

The urban region consists of locations sufficiently close to the core as to be more attractive than an alternative city even when they have occupied neighbors. Thus, these locations must be occupied by rational immigrants. The frontier consists of locations that are sufficiently remote that they are less attractive than an alternative city even if they have no occupied neighbors. It follows that these locations cannot be occupied by rational immigrants.

The suburbs are marginal urban land. Suburban locations are sufficiently remote that they are only more attractive than an alternative city if they have no occupied neighbors. To see that alternate spaces must be occupied in an equilibrium suburb, note that an immigrant at a suburban location who does not obtain open space benefits is strictly better off deviating to an alternate city, so that no adjacent occupied spaces are possible in the suburbs. If two adjacent vacant spaces occur in the suburbs, then the next most extreme immigrant can deviate and move closer to the core without compromising his access to open space so that no adjacent open spaces are possible in the suburbs. Since adjacent vacant and adjacent occupied locations are not possible in equilibrium suburbs, it follows that alternate suburban locations are occupied. 
By inspection of theorem 1 and figure 1, we see that the location of the suburbs is determined by the gap between the wage in the subject city and the utility of the alternate city, while the width of the suburbs is determined entirely by the value of open space.

Figure 1 also makes clear the reason for assuming that neither $w-u_{\theta}$ nor $w-u_{\theta}+\delta$ are integers. If this condition is violated, the critical values of $y$ where the bid-rent curves $w-y$ and $w-y+\delta$ are exactly equal to $u_{\theta}$ coincide with lot locations. This raises the possibility that there will be two locations in $Y$ that are exactly indifferent, and hence the possibility of multiple equilibria. In fact, absent this assumption multiple equilibria may arise, though each of them is very similar to the unique equilibria that obtain in the rest of the parameter space. Thus, the object of the assumption that neither $w-u_{\theta}$ nor $w-u_{\theta}+\delta$ are integers is to simplify the statement of the theorem.

\section{B. Simultaneous arrival game with a land market}

Now consider a market for residential land that operates in two stages. In the first stage, all landlords simultaneously choose prices. In the second stage all immigrants simultaneously choose locations and pay the price associated with that location. All landlords whose locations are ultimately unoccupied receive the price associated with the best alternative use of their land. The two stage, 'Bertrand', operation of the land market allows immigrants an opportunity to respond to a landlord's price deviations. Without such an opportunity, unilateral price changes could not have an effect on immigrant location choices.

Immigrants are restricted to choose pure strategies, so that a strategy for an immigrant is a mapping from an observed price and location profiles into the set of possible locations, i.e., $S_{i}\left(P, X_{-i}\right) \in Y \bigcup\{\theta\}$. Landlords are also restricted to choose pure strategies, so that a strategy for a landlord is a mapping from the set of price profiles into the set of non-negative real numbers. That is, $S_{y}\left(P_{-y}\right)=p_{y}$. Let $\left(P^{*}, X_{N}^{*}\right)$ denote a subgame perfect equilibrium choice of prices and locations by landlords and immigrants.

Theorem 2 characterizes the unique location profile and price gradient that result when immigrants play Nash equilibrium strategies, taking prices as given, and the landlords also play Nash

equilibrium strategies, correctly anticipating the immigrants' responses, i.e., a subgame perfect equilibrium. Like theorem 1, theorem 2 makes the simplifying assumption that neither $w-u_{\theta}$ nor $w-u_{\theta}+\delta$ are integers. Relaxing this assumption does not qualitatively change the results, but does create the possibility of multiple equilibria. Like theorem 1, theorem 2 also supposes that the set immigrants is large in order to avoid considering trivial equilibria that occur with small numbers of agents.

Theorem 2 Assume that neither $w-u_{\theta}$ nor $w-u_{\theta}+\delta$ are integers and that $n>w-u_{\theta}+\delta$. A price and location profile $\left(P^{*}, X_{N}^{*}\right)$ is an equilibrium if and only if the following conditions hold:

1. All locations $y \leq \underline{y}$ are occupied, where $\underline{y}=\operatorname{int}\left(w-u_{\theta}\right)$.

2. All spaces $y>\bar{y}$ are vacant, where $\bar{y}=\operatorname{int}\left(w-u_{\theta}+\delta\right)$.

3. Alternate spaces are occupied in the region $\{\underline{y}+1, \ldots, \bar{y}\}$. 
4.

$$
p_{y}^{*}= \begin{cases}w-u_{\theta}-y & \text { if } y \leq y \\ w-u_{\theta}-y+\delta & \text { if } y \in\{\underline{y}+1, \ldots, \bar{y}\} \text { and } y \text { occupied } \\ 0 & \text { if } y \text { vacant. }\end{cases}
$$

Theorem 2 establishes that the simultaneous arrival game has a unique equilibrium outcome of the form illustrated in figure 2. An equilibrium development profile consists of three regions. An urban region near the old city limit which is solidly occupied, a more extreme suburban region where only alternate spaces are occupied, and an unoccupied frontier. The land price gradient slopes down from the origin until the beginning of the suburbs, where it increases discretely to $\delta-2$. In the suburbs, the land price gradient decreases with distance from one occupied space to the next, but is zero at all unoccupied spaces. Depending on the magnitudes of $\delta$ and $w$, land prices are highest at the least extreme urban location, $y=1$, or at the least extreme occupied suburban location, $y=\underline{y}+2$.

The location profile described in theorem 2 is identical to the one described in theorem 1 . The introduction of a land market serves only to change the division of land rents. With a land market all land rents are captured by landlords, while land rents are captured by immigrants when land trades at its opportunity cost. The intuition behind theorem 2 is described below.

In the urban region an immigrant who occupied an urban location at a zero price would receive land rents exactly equal to $p_{y}^{*}$, so that a landlord in this region who sets his price above $p_{y}^{*}$ assures that all immigrants prefer the alternate city to his location. Such a landlord is better off if he deviates and chooses a small positive price in order to attract an immigrant. If a landlord chooses a price below $p_{y}^{*}$ he assures that his location is strictly more desirable than the alternate city and hence that it is occupied in equilibrium. Such a landlord can deviate to a slightly higher price without risk of his location being left vacant. Two possibilities remain, that an urban landlord chooses price $p_{y}^{*}$ and an immigrant chooses his location, or that an urban landlord chooses $p_{y}^{*}$ and his location goes unoccupied. Suppose a landlord chooses $p_{y}^{*}$ and no immigrant chooses his location. Then the landlord should deviate to a slightly lower price to attract an immigrant. The only possibility remaining is that the urban landlord chooses $p_{y}^{*}$, and an immigrant occupies his location. It follows that in equilibrium all urban locations must be occupied and the price must be such that immigrants are indifferent between urban locations and the alternate city.

Next consider the frontier region. For any non-negative land price the alternate city is more attractive to immigrants than any frontier location, even if the frontier location does not have occupied neighbors. Thus, the only way that a landlord could attract an immigrant is to offer a subsidy. This is not in the landlord's interest and so equilibrium requires that all frontier locations be unoccupied.

Finally, consider the suburban region. The suburb consists of locations where agents prefer the alternate city to a suburban space with an occupied neighbor at any positive price. Thus adjacent suburban spaces can only be occupied if landlords offer negative prices. Adjacent vacant spaces are also not possible. If three adjacent spaces are vacant then the middle landlord can deviate to a small positive price and attract an immigrant. Therefore, if two adjacent spaces are vacant, say 


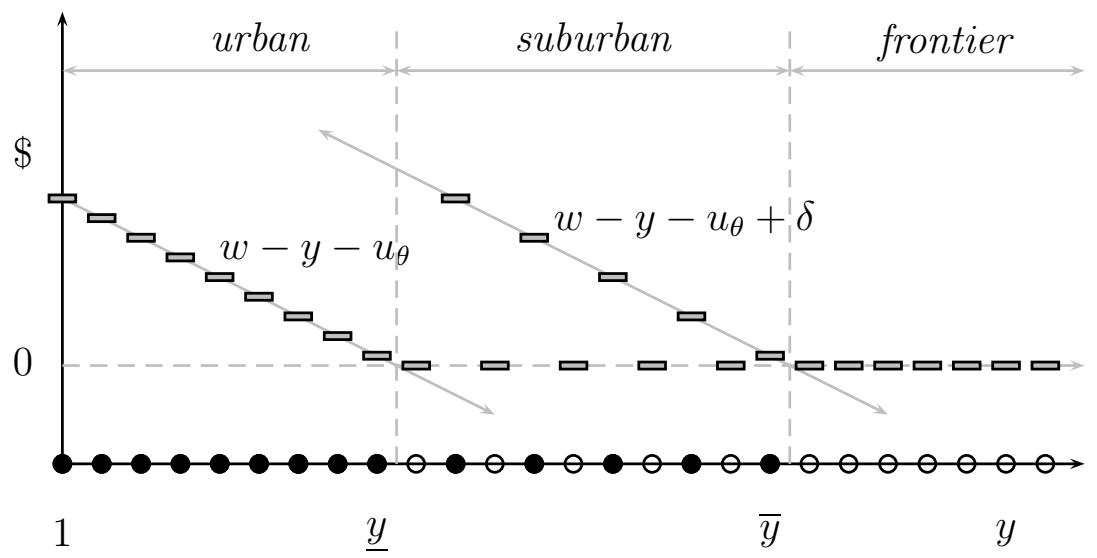

Figure 2. A characteristic equilibrium location and price profile for the simultaneous arrival game with a land market. Circles indicate vacant locations, discs indicate occupied locations. Bars indicate the price at a given location. Rents vary with location so that all immigrants are indifferent between their location and the alternate city.

$y$ and $y+1$, then $y+2$ must be occupied. In this case, landlord $y+1$ can deviate to any price less than $p_{y+2}+1$ and provide the immigrant at $y+2$ with an incentive to deviate to $y+1$. Since $p_{y+2}+1>0$ (as long as landlord $y+2$ is not providing an irrational subsidy) such a deviation is in landlord $y+1$ 's interest. Since adjacent vacant and adjacent occupied spaces are prohibited, it follows that vacant and occupied spaces must alternate in equilibrium. Equilibrium prices are set so that suburban immigrants are indifferent between the alternate city and the suburbs. The intuition for this is the same as the intuition that leads prices in the urban region to adjust so that immigrants are indifferent between the urban region and the alternate city.

As odd as it is, the equilibrium price gradient predicted by this model manages to correctly reflect the value of both commuting costs and open space. However, the sharp jump up in land prices at the boundary of the suburbs is in part an artifact of the model. If immigrants' open space benefits increased continuously with the amount of nearby open space this effect would probably be considerably smoothed. On the other hand, the fact of alternating zero and positive land prices in the suburbs does not appear to be an artifact of simplifying assumptions.

To increase legibility, I earlier set the opportunity cost of land to zero. This means that immigrants are indifferent between buying vacant lots and not buying them, and the distinction between public open space and private land becomes unclear. However all of the results presented here persist, mutatis mutandis, with a strictly positive opportunity cost of land, so that this problem should be regarded as following directly from simplifying assumptions, and not as a signal of problems with the model.

\section{Sequential arrival game with land market}

Now consider the case when immigrants arrive sequentially rather than simultaneously. In period 1 landlords choose prices. During period 2, the $n$ potential immigrants arrive sequentially and either choose a location or move to a different city. In period 3, all immigrants finalize their transactions and occupy their locations. Since an immigrant's location choice during period 2 


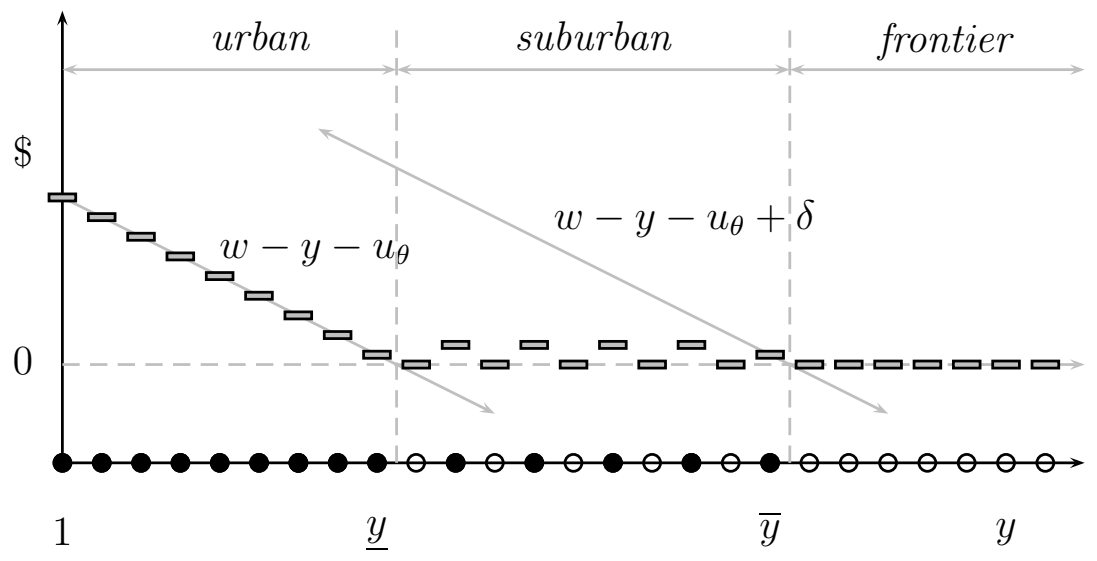

Figure 3. A characteristic equilibrium location and price profile for the sequential arrival game. Circles indicate vacant locations, discs indicate occupied locations. Bars indicate land prices at a given locations. Land prices vary with location so that all urban residents are indifferent between their location and the alternate city, but suburban residents capture nearly all land rent.

is irrevocable, this model is consistent with a large implicit fixed cost of moving and I imagine immigrants in this game as purchasing rather than renting land.

While arrival times are explicitly modeled, the model is not fully dynamic in three regards. First, immigrants' payoffs depend only on the final arrangement of immigrants, so there is no incentive to choose a more extreme location in order to secure a few periods without neighbors. Second, landlords are indifferent between selling their parcel to the first immigrant or to the last. These two assumptions are consistent with examining the pattern of location choice over a time horizon that is very short relative to the time that houses will be occupied. Third, landlords are constrained not to adjust their prices as play progresses. This assumption does not affect the outcome of the game and is relaxed in section 4 . It is maintained here to simplify notation and exposition.

Like the immigrants of the simultaneous arrival game, immigrants in the sequential arrival game derive utility from income, disutility from commuting, and, utility from their proximity to open space. As before, $i$ indexes the set of potential immigrants, but now also gives an immigrant's order of arrival. Thus, $i(y)$ gives both the name and arrival time of the immigrant at location $y$. Let $X_{i}$ denote the set of occupied locations after all immigrants $1, \ldots, i-1$ have moved. As before, $X_{N}$ denotes a list of occupied locations after all $n$ potential immigrants choose a location.

A strategy $S_{i}$ for immigrant $i$ is a function from the set of possible location and price profiles at $i$ into the set of possible locations. That is, $S_{i}:\left(P, X_{i}\right) \rightarrow Y \bigcup\{\theta\} . S_{N}$ denotes a strategy profile for all immigrants. Note that this imposes a mild restriction on immigrants' behavior: immigrants are permitted to condition only on the location profile that they face, not on the history of play that led to this profile. This assumption requires that immigrants be unaware of the course of play that precedes their arrival, and prevents immigrants from exploiting the repeated nature of the game.

Landlords are also restricted to choose pure strategies. A strategy for a landlord is a mapping from the set of price profiles into the set of non-negative real numbers. That is, $S_{y}\left(P_{-y}\right)=p_{y}$. If no homeowner chooses a landlord's location then the landlord receives the prevailing price in the best non-residential land use. As before, this price is normalized to zero to increase legibility. 
$S_{Y}$ denotes $\left(S_{y}\right)_{y=1}^{m}$, a strategy profile for all landlords. A strategy profile for the game is a pair $\left(S_{Y}, S_{N}\right)$, and an equilibrium profile is denoted $\left(S_{Y}^{*}, S_{N}^{*}\right)$. Theorem 3 now provides restrictive necessary conditions for a subgame perfect equilibrium of this game.

Theorem 3 Assume that $n>w-u_{\theta}+\delta$. Let $y=\operatorname{int}\left(w-u_{\theta}\right)$, and let $t$ be the largest integer satisfying $2 t<\delta$. Along any equilibrium path immigrants 1 to $t$ occupy locations $(\underline{y}+2, \underline{y}+4 \ldots, \underline{y}+2 t)$. The remaining immigrants occupy spaces $1, \ldots, \underline{y}$ or $\theta$ in any order.

Equilibrium land prices satisfy:

$$
p_{y}^{*}=\left\{\begin{array}{lll}
w-y-u_{\theta} & \text { if } & y \in\{1, \ldots, \underline{y}\} \\
\min \left(1, w-u_{\theta}+\delta-y\right) & \text { if } & y \in\{\underline{y}+2, \underline{y}+4, \ldots, \underline{y}+2 t\} \\
0 & \text { else. }
\end{array}\right.
$$

Theorem 3 establishes that any equilibrium of the sequential arrival game has an outcome of the form illustrated in figure 3. As in the two earlier games, an equilibrium development profile consists of three regions. An urban region near the old city limit which is solidly occupied, a more extreme suburban region where only alternate spaces are occupied, and an unoccupied frontier. Land prices in the urban region adjust so that immigrants are indifferent between the target city and the alternate city. In the suburban region the transaction price of an occupied lot is exactly equal to one, except for the most extreme suburban location which may have a price less than one. Unoccupied suburban lots have price zero. Finally, in any equilibrium of the sequential arrival game, the first immigrant occupies the first suburban space, $y+2$, the second immigrant occupies the second suburban space, $y+4$, and so on until alternate suburban locations are all occupied. The remaining immigrants distribute themselves across the urban region and the alternate city in any order.

Comparing the equilibria of the simultaneous arrival game with those of the sequential arrival game we see that equilibrium patterns of location and urban land prices are identical, but that suburban land prices are different. In the simultaneous arrival game land prices jump up discretely at the interior edge of the suburb (e.g., location $\underline{y}+2$ in figure 2). This price jump does not occur in the sequential arrival game. Finally, the sequential arrival game allows predictions about the order in which locations are occupied. By construction, such results are not possible in the static game.

The main ideas in the proof of theorem 3 follow. As in the earlier results, the urban region consists of those locations that an immigrant prefers to the alternative city at a non-negative price even if the location has occupied neighbors. Similarly, the suburban region consists of those locations that an immigrant prefers to the alternative city at a non-negative price only if the location does not have occupied neighbors.

To begin, assume that equilibrium prices in the urban region are such that immigrants are indifferent between the urban region and the alternate city. It follows that immigrant one is indifferent between the alternate city and any urban space. Suppose that immigrant one occupies $\underline{y}+k$ for $k>2$ and pays price $p_{k}$. It follows that no subsequent immigrant will occupy the adjacent interior location $\underline{y}+k-1$ at any positive price and that this landlord receives zero payoff. The landlord at location $\underline{y}+k-1$ can deviate to price, $p_{y+k-1}=p_{y+k}+\alpha$ for $\alpha \in(0,1)$. Immigrant one should respond by deviating to this location, leaving location $\underline{y}+k$ vacant and assuring landlord 
$\underline{y}+k$ a zero payoff. Since this competition from the adjacent less extreme landlord must occur at every suburban location other than $\underline{y}+2$, where the next less extreme location is uninhabitable at a non-negative price, it follows that the first immigrant must choose $\underline{y}+2$ if he chooses a suburban location.

While the landlord at $\underline{y}+2$ does not face competition from the adjacent less extreme landlord, he does face competition from the adjacent more extreme landlord. If landlord $\underline{y}+2$ chooses a price greater than one, then landlord $\underline{y}+3$ can offer a low enough price to attract immigrant one. It follows that if immigrant one occupies a suburban location, this suburban location is $\underline{y}+2$ and the transaction price is one. Since the price of $\underline{y}+2$ is one, it follows that the immigrant retains some of the land rent and strictly prefers this location to the alternate city or to the urban region. Thus, immigrant one must occupy $\underline{y}+2$. Similar logic assures that subsequent immigrants occupy successive alternate suburban locations at low prices.

It remains to justify my initial assumption on urban land prices. Given that competition amongst suburban landlords leads them to pass most land rent to the immigrants, urban landlords can only attract one of the early immigrants by outbidding the suburban landlord. On the other hand, after the suburban locations are filled, the only competition for urban locations is the alternate city. Since landlords are not impatient ${ }^{7}$ it makes sense for them to avoid competing with the suburban landlords. In fact, after the suburban locations are occupied, the intuition underlying the choice of urban land prices is the same as that which operates in the simultaneous arrival game.

The finding of low suburban land prices is interesting enough that a more heuristic explanation is also justified. Suburban land is marginal urban land that is only valuable in residential use if its neighbors are unoccupied. This means that adjacent landlords have powerful incentives to compete, since only the landlord who attracts an immigrant first will receive a positive payoff. In this model, it is always the more central landlord who wins this competition since his location has lower commute costs. This leads to the equilibrium described by theorem 3 where less remote suburban locations are occupied first and where suburban land prices reflect only the cost of commuting a unit distance.

The low suburban land prices that occur in this model are striking because they describe a land price gradient in which not all land rent accrues to landlords in equilibrium. This is a peculiar characteristic for an equilibrium location pattern, and my intuition is that it should be relevant the very first time that a land transaction will lead to development, e.g., the sale of a lot, and hence commits the neighborhood to a pattern of residential location. Subsequent sales of the location (which are not modeled here) occur after development patterns are set and should not be expected to conform to the predictions of theorem 3.

The low transaction prices of suburban land come about because suburban landlords compete to attract immigrants before their neighbors do. In this model, landlords are only able to compete by lowering the asking price of their lots. In practice, we should expect to see other responses to this problem, e.g., preemptive building in advance of demand, or the development of larger parcels. Thus, the finding in theorem 3 that suburban land prices are low, is interesting because it

\footnotetext{
${ }^{7}$ It is important that landlords are not impatient. Otherwise they would have an incentive to cut their prices to attract an earlier immigrant. As we will see later, this complicates matters considerably.
} 
is a symptom of an underlying incentive problem. Although it is beyond the scope of this paper, it is clearly of interest to consider responses to this problem other than price competition.

A consequence of low suburban land prices is that not all immigrants have the same utility level in an equilibrium city. This is of considerable interest. A nearly universal assumption in theoretical analyses of cities is that all city residents obtain the same level of utility in equilibrium. ${ }^{8}$ The current contradictory finding suggests the need to revisit existing theoretical models of location choice in the presence of landscape externalities.

Since an immigrant actually 'moves in' after all immigrants have chosen a location, the move order has no welfare consequences in this game. Nevertheless, the order of play is noteworthy. In any equilibrium, immigrant one occupies the nearest suburban location, while subsequent immigrants occupy progressively more remote suburban locations. After the suburban region is 'full', successive immigrants occupy urban locations in any order. The finding that suburbs are occupied before interior locations foreshadows a similar result in a fully dynamic model. However, in the dynamic model, such large scale 'leapfrogging' will have important welfare implications.

\section{The optimal static city}

For a given location profile $X_{N}$, I now let $\chi\left(y, X_{N}\right)$ be an indicator variable that is zero if location $y$ has a neighbor in location profile $X_{N}$, and one if it does not. Define the social surplus of location profile $X_{N}$ to be

$$
W\left(X_{N}\right)=\Sigma_{y \in X_{N}}\left(w-y+\chi\left(y, X_{N}\right) \delta-u_{\theta}\right) .
$$

That is, $W\left(X_{N}\right)$ is the most that the potential immigrants would pay, in aggregate, for the opportunity to settle in the subject city. An optimal location profile, $X_{N}^{* *}$, is the one that maximizes this surplus, i.e., $X_{N}^{* *}$ solves $\max _{X_{N} \subset Y} W\left(X_{N}\right)$.

Theorem 4 characterizes the unique optimal location profile for the three static location games already analyzed. As before I exclude from consideration economies where $w-y-\delta$ or $w-y+\delta$ are integers or where the number of potential immigrants is small.

Theorem 4 Suppose that $w-y-\delta$ and $w-y+\delta$ are not integers and that $n>w-u_{\theta}+\delta$. Then there is a unique optimal location profile, $X^{* *}$, and this profile satisfies the following three conditions:

1. All $y \leq \underline{y}^{* *}$ are occupied, where $\underline{y}^{* *}=\operatorname{int}\left(w-u_{\theta}-\delta\right)$.

2. All $y>\bar{y}$ are vacant, where $\bar{y}=\operatorname{int}\left(w-u_{\theta}+\delta\right)$.

3. Alternate locations are occupied in the set $\left\{\underline{y}^{* *}, \ldots, \bar{y}\right\}$.

Theorem 4 establishes that the unique optimal location profile is of the form illustrated in figure 4. An optimal city consists of three regions. An urban region near the old city limit which is solidly occupied, a more extreme suburban region where only alternate spaces are occupied, and

${ }^{8}$ D. E. Wildasin [35] gives conditions under which a utilitarian planner's optimum need not result in equal utility levels for identical agents living in a monocentric city. This is different from the current result where unequal utility levels emerge in equilibrium. 


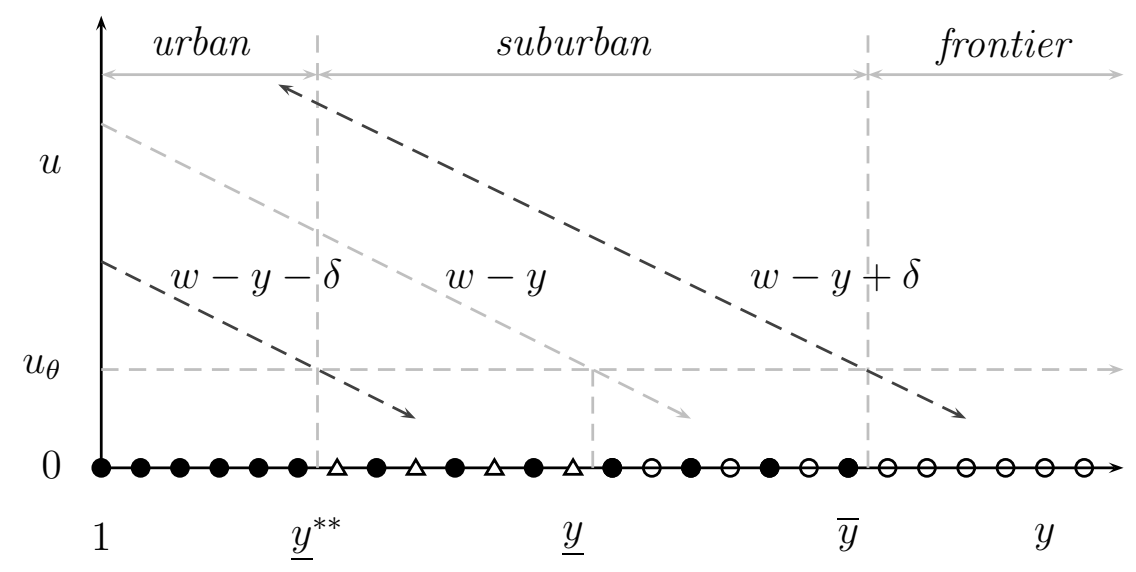

Figure 4. A characteristic optimal location profile. Discs indicate occupied locations. Circles indicate vacant locations under efficient and optimal locations. Triangles indicate locations which are vacant in the optimal but not the equilibrium outcome.

an unoccupied frontier. That is, an optimal city has the same form as the equilibrium city that arises under each of the land markets considered so far. Moreover, the suburban/frontier boundary is the same in the optimal and equilibrium cities. The optimal city differs from the equilibrium only in the location of the urban/suburban boundary. In an optimal city, this boundary occurs about $\delta$ locations nearer to the core than in an equilibrium city. Thus, the optimal suburb is larger than an equilibrium suburb, and the optimal urban region is smaller. Equilibrium cities are too populous and too dense.

To understand this result, note that preferences over open space lead naturally to 'landscape externalities'. When immigrants have a taste for open space, if immigrant A locates next to immigrant B, then immigrant A imposes a cost on B by depriving him of what was previously open space. In the context of figure 4, this means that (given the choice) an immigrant in the alternative city would move to the least remote vacant space since doing so results in a utility level strictly greater than $u_{\theta}$. However, if the immigrant occupying this location were required to compensate his neighbors for their resulting loss of open space, such a move would cease to be attractive. Thus, we see in figure 4 , that the suburbs optimally begin when locations are sufficiently remote that $w-y-\delta<u_{\theta}$. In equilibrium, the suburbs begin further out, where $w-y<u_{\theta}$ and the private benefits of proximity are all that is considered.

Theorem 4 and figure 4 show that equilibrium cities are too populous and too dense. The natural policy response to this is to create parks near the urban/suburban boundary, at locations that should optimally be left open, i.e., the triangles in figure 4 . It is easy to see that creating such a series of parks leads to an equilibrium city which coincides with the optimum in the simultaneous or sequential arrival game. Conversely, a policy which provides incentives for infill development of vacant locations near the equilibrium urban/suburban border is welfare decreasing.

This analysis also suggests that the creation of 'greenbelts' by prohibiting development in wide regions of the suburbs, will not be welfare improving. When a greenbelt prevents immigrants from locating in an extreme portion of the suburbs, these immigrants are displaced to another city, and they (or the owners of the now unoccupied locations) are worse off. Since there is no benefit to the remaining immigrants from the creation of a large vacant region at the city's edge, such greenbelts 
are welfare decreasing. This result should probably be taken literally: A taste for nearby open space does not lead to a policy of green belts. Other sorts of externalities or preferences can lead to such policies, e.g., J. K. Brueckner [32].

\section{Dynamic model}

\section{A. Dynamic game of residential location}

Now consider the fully dynamic $n$ period game. In each period, landlords first simultaneously choose prices. After landlords name prices, an immigrant arrives, selects, pays for, and occupies a location. This game differs from the static game with sequential arrival in that landlords are impatient and the course of play can affect immigrant payoffs. As in the static game with sequential arrival, the fully dynamic game should be regarded as describing only the transactions which determine the pattern of development, e.g., the sale of a lot.

As before, I consider a city which has just experienced a wage shock. $Y=\{1, \ldots, m\}$ denotes the set of available locations, and $y \in Y$ a particular location. The land at each location is owned by a landlord, each of whom owns exactly one location. Index landlords by $y \in Y$ where a landlord's name also gives the location of his parcel.

The set of potential immigrants is $N=\{1, \ldots, n\}$. Immigrant 1 arrives in period 1 , immigrant 2 arrives in period 2, and immigrant $i$ arrives in period $i$. Upon arrival potential immigrants choose a location in $Y$ or go to another city $\theta$. As before, immigrant $i$ 's choice of location is $y_{i} \in Y \cup\{\theta\}$ and $i(y)$ denotes the immigrant(s) occupying location $y$, with $i(y)=\phi$ if $y$ is unoccupied.

Let $X_{i}$ denote the set of occupied locations after immigrants $1, \ldots, i-1$ have moved, so that $X_{1}=$ $\phi$, and $X_{n}$ is observed by the last immigrant to arrive. Call $X_{i}$ a location profile at time $i . X_{N}$ denotes a location profile for the game, a list of occupied locations after all $n$ potential immigrants have made their choice of location.

Landlords choose an asking price in each period and are restricted to choose pure strategies. Let $p_{y}^{i}$ be a choice of asking price for landlord $y$ for period $i, P^{i} \in R_{+}^{m}$ an asking price profile for period $i$, and, $P_{-y}^{i}=P^{i} / p_{y}$ a choice of asking prices for all landlords but $y$ in period $i$. Note that landlords name $n$ prices over the course of the game, so it is necessary to distinguish between transaction prices and asking prices. ${ }^{9}$

Immigrant $i$ 's strategy specifies a choice of location depending on the available vacant locations and the current profile of asking prices. Thus, a strategy for immigrant $i$ is a mapping,

$$
S_{i}:\left(P^{i}, X_{i}\right) \longrightarrow Y \bigcup\{\theta\}
$$

A landlord's strategy specifies a price in each period, depending on the available locations in the period, and the current profile of asking prices by other landlords. A landlord's strategy may also vary with the period of play. A strategy for landlord $y$ in period $i$ is a mapping,

$$
S_{y}^{i}:\left(P_{-y}^{i}, X_{i}\right) \longrightarrow R_{+}
$$

\footnotetext{
${ }^{9}$ To simplify notation, landlords continue to name prices in periods after their location is occupied. However, these prices are irrelevant to the play of the game since no location is ever occupied by two immigrants.
} 
Thus, a strategy $S_{y}$ for landlord $y$ is a sequence $S_{y}=\left(S_{y}^{t}\right)_{t=1}^{n}$ of such mappings, one for each period. A strategy profile for all landlords is denoted $S_{Y}$, a strategy profile for the game, by the pair, $\left(S_{Y}, S_{N}\right)$, and a subgame perfect equilibrium strategy profile by $\left(S_{Y}^{*}, S_{N}^{*}\right)$.

Agents are constrained to choose pure strategies. Agents are also required to condition only on the location profile and asking price profile that they face and not on the course of play that leads to it. Essentially this is a requirement that landlords have no memory, and that immigrants have no information about the course of play that precedes their arrival. The object of these assumptions is to prohibit players from employing strategies which take advantage of the repeated nature of the game. In a game with large numbers of players, like the one envisioned here, these are intuitive restrictions.

Starting with the period when they arrive in the city, an immigrant's utility in each period is given by equation 1, and immigrants discount future utility with discount factor $\gamma \in(0,1)$. Define $k_{N}\left(y, X_{i}, S_{Y}, S_{N}\right)$ to be the number of periods until an immigrant locating at $y$ in period $i$ has a neighbor, given that he faces location profile $X_{i}$ and immigrant and landlord strategy profiles $\left(S_{Y}, S_{N}\right)$. Then an immigrant's utility is,

$$
\begin{aligned}
U_{i}\left(y_{i}, k_{N}\right) & =\Sigma_{t=0}^{k_{N}-1} \gamma^{t}\left(w-y_{i}+\delta\right)+\Sigma_{t=k_{N}}^{\infty} \gamma^{t}\left(w-y_{i}\right)-p_{y}^{i} \\
& =\frac{1}{1-\gamma}\left(w-y_{i}-\left(1-\gamma^{k_{N}}\right) \delta\right)-p_{y}^{i} .
\end{aligned}
$$

Note that this formulation of preferences treats land prices as an asset price rather than a rental price. This is consistent with the notion that location choices in this game correspond to house or lot purchases.

Landlords maximize the discounted present value of the sale of their land, taking the start of the game as time zero. Let $k_{Y}\left(y, X_{i}, S_{Y}, S_{N}\right)$ be the number of periods until location $y$ is occupied, when a landlord faces location profile $X_{i}$ and price profiles and location decisions are determined by strategies $S_{N}$ and $S_{Y}$. A landlord's payoff is given by $\Pi_{y}=\gamma^{k_{Y}} p_{y}$.

Theorem 5 provides necessary conditions for an equilibrium of the dynamic residential location game.

Theorem 5 Let $\bar{y}=\operatorname{int}\left(w-(1-\gamma) u_{\theta}+\delta\right)$ and $\underline{y}=\operatorname{int}\left(w-(1-\gamma) u_{\theta}\right)$. If $n>\bar{y}$ then any equilibrium of the dynamic game satisfies:

1. In any equilibrium location profile $X_{N}^{*}$ all spaces $y>\bar{y}$ are vacant.

2. In any equilibrium location profile $X_{N}^{*}$ all locations $y \leq y$ are occupied, and they are occupied before any immigrant chooses $\theta$.

3. Before any immigrant chooses $\theta$ alternate spaces are occupied in the region $\{y+1, \ldots, \bar{y}\}$, with $y+2$ occupied first and progressively more extreme alternate locations occupied in sequence.

Theorem 5 states that after play is complete an equilibrium location profile has the same form in the dynamic game as it has in the static games with three minor changes. First, $(1-\gamma) u_{\theta}$ replaces $u_{\theta}$ in the definitions of $\bar{y}$ and $y$. This is simply the conversion of a lump sum into a stream: $\sum_{t=0}^{\infty} \gamma^{t}\left((1-\gamma) u_{\theta}\right)=u_{\theta}$. Second, theorem 5 is weaker than the corresponding theorem for the sequential arrival game (theorem 3), in that it does not require that suburban spaces be occupied 
before urban spaces. Rather it requires that less remote suburban spaces be occupied before more remote suburban spaces. Unlike the patient landlords of the static game with sequential arrival, impatient urban landlords may be unwilling to wait until all suburban locations are occupied before attracting an immigrant, so that urban locations may be occupied before the suburbs are full. Third, theorem 5 requires that no immigrant choose $\theta$ until the city is full. In the dynamic game, landlords are impatient to have their locations occupied. Should any immigrant choose $\theta$ before a desirable location was filled, that landlord has an incentive to bid down the land price until the wayward immigrant comes back to the subject city. This is not a requirement of theorem 3 , since a landlord in the sequential arrival game is indifferent about which immigrant occupies his location.

Theorem 6 provides necessary conditions that must be satisfied by suburban transaction prices in any equilibrium of the dynamic game.

Theorem 6 Let $\bar{y}=\operatorname{int}\left(w-(1-\gamma) u_{\theta}+\delta\right)$ and $\underline{y}=\operatorname{int}\left(w-(1-\gamma) u_{\theta}\right)$. If $n>\bar{y}$, then in any equilibrium of the dynamic game, if immigrant $i$ chooses location $y \in\{\underline{y}, \ldots, \bar{y}\}$ then $p_{y}^{i} \leq \frac{1}{1-\gamma}$.

Theorem 6 establishes that, while landlords may ask other prices during periods when their location does not trade hands, in any period when an immigrant buys a suburban location, the transaction price can be no greater than the discount present value of a one unit increase in commuting distance. The intuition underlying this result is identical to that which leads to low suburban land prices in the static game with sequential arrival. Suburban locations transact at low prices because landlords must compete with neighboring landlords in order to attract a resident and avoid being left with a vacant location at the end of the game.

A comment about the structure of the land market is appropriate here. By assumption, only one immigrant is permitted to purchase land in each period. For example, in period two only immigrant two may purchase a lot (or choose the alternate city), immigrant one is prohibited from changing his location even if such a change is desirable. Two justifications for this prohibition of relocation are possible. First, the transactions costs associated with buying and selling residential real estate are large. Imagining that these costs are large enough to prohibit moving is a reasonable, though coarse, approximation to the barrier that transactions costs impose on a potential mover. Alternately, the restriction on relocation may be regarded purely as a simplifying assumption. In this case it is interesting to consider what would happen if we were to relax the restriction and allow all immigrants to relocate in each period. Although a proof is beyond the scope of this paper, I conjecture that relaxing this assumption would have no effect at all on patterns of location or on transaction prices for previously unoccupied lots. ${ }^{10} 11$

\footnotetext{
${ }^{10}$ This conjecture is based on the following observation. When immigrants are permitted to relocate they essentially assume the role of landlords in the periods after they first locate in the city. This transforms the dynamic game into a sequence of games that look like the static game with simultaneous arrival, save that each successive game involves one more player. Once such a game becomes large enough that the suburban locations are being occupied, each successive period will see one more suburban location occupied at the previous suburban frontier. Since these spaces are at the very edge of the city the next more remote location remains unoccupied, so that these locations cannot command a price greater that the cost of commuting to this next more remote location. This will lead to a final location pattern and suburban land transaction prices that are consistent with theorems 5 and 6.

${ }^{11}$ It is worth pointing out that theorem 6 places restrictions only on the prices at which transactions occur in the period when the transactions occur. This is subtly different from a rent gradient. In this model, a rent gradient would consist of prices for each location in a particular time.
} 
Theorem 5 gives necessary conditions for the final location profile resulting from subgame perfect equilibrium play of the dynamic game. Theorem 6 gives necessary conditions for suburban land transaction prices resulting from equilibrium play. Neither theorem sheds any light on the order in which locations are occupied. Theorem 7 provides additional necessary conditions which restrict the order in which locations are occupied in any equilibrium play of the dynamic game.

Theorem 7 Let $\underline{y}=\operatorname{int}\left(w-(1-\gamma) u_{\theta}\right)$ and $l \in\{0, \ldots, \underline{y}\}$ an integer. Suppose $n>w-(1-\gamma) u_{\theta}+\delta$ and $\delta>\frac{l}{\gamma^{n}}$. Then, in any equilibrium, all $y \in\{\underline{y}-l, \ldots, \underline{y}\}$ are occupied after the first suburban location, $\underline{y}+2$, is occupied.

Theorem 7 provides a partial characterization of the order in which locations are occupied. In particular, it gives conditions under which the first suburban location must be occupied before the $l$ most extreme urban locations. These conditions are that the set of immigrants is sufficiently large that all urban locations are occupied at the end of the game and that the value of open space is larger than the discount present value of commuting a unit distance during the $n$ periods of the game. Note that theorem 7 makes a stronger statement than that development and vacant locations will alternate in the suburbs. In addition to the alternate vacant spaces that persist in the final arrangement of the suburbs, early immigrants may locate at relatively remote locations, 'leapfrogging' over many undeveloped locations in the process.

The intuition behind theorem 7 is nearly identical to that which explains why the suburbs must be occupied in advance of the urban region in the static game with sequential arrival. Given theorem 6, an immigrant who locates at the interior edge of the suburb pays a low price, and thereby captures most of the land rent due to this location. Slightly less extreme urban landlords do not need to compete for immigrants who want these attractive locations since they are assured that, eventually, an immigrant will buy their location. Thus, immigrants at these locations do not capture as much land rent. It follows that suburban locations may be more attractive to immigrants than are slightly less extreme urban locations and hence may be occupied earlier. Unlike the static game with sequential arrival, however, urban landlords are impatient and it remains possible that an urban landlord will want to attract an immigrant before all of the suburban locations are filled.

Thus, theorem 7 is consistent with (but does not guarantee) a sequence of location choices in which the urban region develops continuously out from the city center while the suburban region simultaneously develops in alternate location outward from the final urban/suburban frontier. This sequence of location choices would leave a large undeveloped gap between the urban and suburban regions that is not filled until late in the development process.

\section{B. The optimal dynamic city}

To construct a measure of dynamic optimality, I apply the static notion in each period and then discount each period's welfare back to the beginning of the game. In each period of play the surplus generated by the dynamic city is the same as would be generated by the corresponding static city with location profile $X_{i}$, i.e., equation 2 . Thus,

$$
W\left(X_{i}\right)=\Sigma_{y \in X_{i}}\left[w-y-\chi\left(y, X_{i}\right) \delta-(1-\gamma) u_{\theta}\right]
$$


The total welfare for a particular course of play is the discounted sum of each period's welfare,

$$
W^{N}\left(\left(X_{i}\right)_{i \in\{1, \ldots, n, N\}}\right)=\sum_{i=1}^{n} \gamma^{i-1} W\left(X_{i}\right)+\sum_{i=n}^{\infty} \gamma^{i} W\left(X_{N}\right) .
$$

An optimal dynamic city is a sequence of feasible location profiles $\left(X_{i}\right)_{i \in\{1, \ldots, n, N\}}$ that maximizes $W^{N}$.

Given this definition, theorems 8 and 9 provide two necessary conditions for an optimal dynamic city.

Theorem 8 Let $\underline{y}^{* *}=\operatorname{int}\left(w-(1-\gamma) u_{\theta}-\delta\right)$. If $\left(X_{i}^{* *}\right)_{i \in\{1, \ldots, n, N\}}$ is an optimal sequence of location profiles and $\delta>\overline{1}$, then for all $i$ no two adjacent locations more extreme than $\underline{y}^{* *}$ are occupied in $X_{i}^{* *}$.

Like the corresponding theorem for the static game, theorem 4, theorem 8 requires that an optimal city contain empty spaces closer to the core than are present in an equilibrium city. As in the static game, immigrants fail to take account of the costs that they impose on their neighbors when they occupy a vacant location. Thus, like its static counterpart, an equilibrium city resulting from the dynamic location game does not contain enough open space.

In the dynamic game, landlords care about when they sell their land, and immigrants care about the number of periods that they are without neighbors. This opens the door to the possibility, not only that the final arrangement of immigrants will be sub-optimal, but that the order in which immigrants fill a certain location profile may also be inefficient. Theorem 9 provides a condition that must be satisfied if such dynamic inefficiency is to be avoided.

Theorem 9 Let $X_{N}^{* *}$ be a socially optimal location profile. Let $y$ and $y^{\prime}$ be two occupied locations in this profile such that $y^{\prime}>y$, and, neither $y$ nor $y^{\prime}$ has neighbors. Then $y$ is occupied before $y^{\prime}$.

The intuition behind this result is simple. A less remote location without neighbors generates more surplus than does a corresponding more remote location. It is easy to see in equation 4 that occupying spaces with more surplus sooner rather than later will lead to higher welfare. It follows that less remote spaces without neighbors must be occupied before more remote locations without neighbors.

We can now see that equilibria of the dynamic game may be dynamically inefficient. From theorem 7, we know that large scale leapfrogging can occur in equilibrium. Moreover, from theorem 8 , some of the locations that are passed over, should optimally be occupied and not have neighbors. Therefore, in the dynamic game an equilibrium development path may deviate from the optimum both because it fails to provide enough interior open space, but also because suburban locations are developed earlier than they should be.

Thus equilibrium deviation from the optimum is more nuanced in the dynamic model than in the static models. In the static models, equilibrium cities contain too many people to close together. That is, the static models are 'not sprawling enough'. In the dynamic model, the same statement is true for the final location profile, but under the conditions of theorem 7, leapfrog development leads the dynamic city to diverge from the optimal development path. That is, the final development profile will not be sprawling enough, but along the path to this final profile the city may be too sprawling. In light of this more nuanced welfare analysis, policy prescriptions from the dynamic model are also more nuanced. 
As in the static model, the creation of small parks slightly less extreme that the final urban/suburban border continues to be welfare improving, policies which promote infilling of vacant locations slightly more extreme than the final urban/suburban border are still not welfare improving, and, permanent greenbelts that restrict the size of the final location profile are still not welfare improving. However, the dynamic model suggests a refinement of these recommendations. The static model indicates that creating small parks in the urban region near the urban/suburban border is welfare improving. The dynamic model suggests that these parks should be created in advance of immigration, and that they should be more extensive. In particular, analysis of the dynamic model suggests that creating a network of small parks that extends from the urban region near the urban suburban boundary all the way out to the frontier is welfare improving.

In the dynamic model, suburban landlords compete with each other to attract immigrants, so that in equilibrium, most of the rent associated with these locations is captured by the immigrant. As a consequence, these suburban locations are very attractive to immigrants and are occupied sooner than they would be in the optimum. If parks were created at alternate suburban locations, then suburban landlords would no longer need to compete with their neighbors to attract immigrants, and would consequently choose prices such that they, rather than the immigrants, capture the land rents at these locations. This would remove the incentive for immigrants 'leapfrog' and move to the suburbs before more interior locations were filled.

An alternate, somewhat coarser strategy is also reasonable. By prohibiting development in outlying areas until the interior is developed at suburban densities, a series of temporary greenbelts could also prevent welfare decreasing leapfrogging. The distinction between such temporary green belts and permanent greenbelts is important. Permanent green belts serve to restrict the final configuration of the city, temporary green belts restrict leapfrog development and require that a city develop outward at a more uniform density.

\section{Private open space}

It is natural to imagine that a big privately owned yard serves its owner as a substitute for nearby public open space. Moreover, people do choose to have yards of different sizes. Thus, I would like to consider patterns of residential location in an environment where people have tastes for public and private open space, and choose both their lot size and their location.

As a first step, we must specify preferences over public and private open space. Any such preferences must deal with two possible types of substitution. First, the substitution of a larger private yard for oneself, for public open space. Second, the substitution of a larger private yard for a neighbor for public open space. ${ }^{12}$ While the empirical literature does provide a basis for thinking about the relationship between the value of own yard size and the value of nearby public land, to

\footnotetext{
${ }^{12} \mathrm{~J}$. K. Brueckner [36] is also concerned with the extent to which yards should be regarded as public or private goods, but does not consider the possibility that people may derive benefits from a neighbor's yard.
} 
my knowledge, this literature has not considered the substitution between public open space and larger yards for one's neighbors. ${ }^{13}$

To analyze residential location choices in this complicated environment, I suppose that nearby public open space is a perfect substitute for one's own private open space, and that a neighbor's private open space is of no value. That is, I imagine that all private open space is surrounded by tall fences, and that these fences prevent neighbors from deriving benefit from the space, but not the owner. A more formal description of these preferences is,

$$
u_{i}\left(y_{i}, p_{y}, X_{-i}\right)= \begin{cases}w-y_{i}-p_{y}+\delta & \text { if } y_{i} \text { is vacant and has no } \\ w-y_{i}-\left(p_{y-1}+p_{y}+p_{y+1}\right)+\delta & \text { occupied neighbors } \\ w-y_{i}-p_{y}-1, y_{i}, y_{i+1} \text { are vacant and } i \text { buys them } \\ -\infty & \text { if } y_{i} \text { is vacant and has at least one } \\ \text { occupied neighbor } \\ u_{\theta} & \text { if } y_{i} \text { is occupied by another immigrant } \\ & \text { if } y_{i}=\theta .\end{cases}
$$

This specification is identical to those given earlier in equation 1, with two exceptions. First, there is the possibility of purchasing three adjacent lots in order to obtain open space benefits. Second, 'occupied neighbor' is either an adjacent residence or an adjacent private open space.

Suppose that all other aspects of the static game with simultaneous arrival and a land market are preserved (see section $3 b$ ), except that the opportunity cost of land is strictly positive. It is now easy to show that the equilibria in this more general game are exactly the same as those in the original game where private open space is exogenously prohibited.

To see this, note that no equilibrium is possible in which an immigrant owns private land. Any immigrant who secures open space by purchasing it is strictly better off deviating to the strategy where he purchases only the location he occupies. In a Nash equilibrium, no other immigrant can respond to this deviation by occupying the newly available spaces, so that they must remain open, and our immigrant enjoys the benefits of open space without paying for the adjacent lot. It follows that no rational landlord will sell land to an immigrant unless the immigrant is going to occupy that location. Since the purchase of open space cannot occur in equilibrium, we are, in effect, returned to the original game and the resulting equilibria are described by theorem 2 .

This finding is simultaneously reassuring and disturbing. The result is reassuring because it means that the equilibria of the simultaneous move game are robust to the possibility of endogenous lot size. Put another way, the finding that equilibria of the static game are robust to the possibility of private open space means that these equilibria are not sensitive to the fixed lot size assumption. Indeed, while the assumption of fixed discrete lots is a strong simplifying assumption, the intuition underlying results presented here should persist in more general models. Equilibrium location patterns presented here are driven by the fact that when people like to be near open space,

\footnotetext{
${ }^{13}$ This may seem like a purely academic detail, but it is actually an important issue. If I am indifferent between having land preserved as open space in a park, and having it preserved as open space in my neighbor's back yard, then zoning for public open space and zoning for small houses on large lots is equivalent.
} 
some land is sufficiently far away from the center that it is only valuable in residential use if nearby parcels are unoccupied. This basic intuition should persist in more complex environments than those treated here.

On the other hand, the finding of no equilibrium provision of private open space is disturbing because the result looks like an artifact of the equilibrium concept employed. The natural response to this problem is to investigate the provision of private open space using one of the other sorts of equilibria. Unfortunately, despite considerable effort, this problem has resisted solution. While I conjecture that a similar result obtains in the static game with sequential arrival, a compelling proof is elusive. $^{14}$

The finding of no equilibrium provision of private open space is also disturbing because it is counterfactual. Different lot sizes are observed, but are not predicted by this model. This suggests a problem with the model. However, given the deliberate simplicity of the model, it should come as no surprise that it fails to predict all aspects of observed development patterns. I conjecture that one of two generalizations could result in equilibria with private provision of open space. The first such generalization would involve the introduction of two classes of agents, wealthy agents with a high cost of commuting and poor agents with a low cost of commuting. Alternately, allowing private open space to be strictly more valuable to its owner than the corresponding amount of public open space might also lead to equilibria with the private provision of open space. These models are the subject of further research.

\section{A back of the envelope calculation}

In all of the equilibria analyzed here the value of open space, $\delta$, corresponds closely to the extent of the suburbs. Therefore, if we can estimate this parameter, we can get a sense for the economic importance of landscape preferences and for the amount of observed open space they can explain. Since the analysis has taken unit commuting costs to be the numeraire, estimating $\delta$ requires an estimate of both of the value of open space and of marginal commuting costs.

While a number of studies provide estimates of the value of access to open space, the estimates presented in E. G. Irwin [12] are best suited to the current purpose. Estimates obtained in P. Cheshire and S. Sheppard [37], while not directly comparable, appear to be of a similar magnitude. Using data on house sales in suburban Maryland, E. G. Irwin [12] estimates that in 1995 converting an average acre of pasture land to residential development, anywhere within a 400m radius of an average house will decrease the house's value by about 1530 dollars. Abusing the marginal nature of this analysis, I calculate that the value of moving from a neighborhood with no open space to

\footnotetext{
${ }^{14}$ The intuition behind this conjecture is as follows. First, one can show that in any equilibrium, the bid rent curve for immigrants who purchase private land must be one third as steep as the bid rent curves for individuals purchasing only one location. Second, one can also show that in any equilibrium all private open space must be less extreme than all public open space. I conjecture that there is no way to satisfy these conditions in a way that involves any positive amount of private open space.
} 
a neighborhood, which is half occupied (like those in this paper) at about 4752 dollars per year. ${ }^{15}$ If a commuter makes 500 one way trips per year, and the marginal cost of a mile of driving is $\mathrm{c}$ then $\delta=4752 / 500 c=9.50 / c$. Thus, even if we assign quite high values to the marginal cost of commuting, resulting estimates of $\delta$ are consistent with low density suburbs whose extent is measured in miles or tens of miles. This suggests that open space preferences are probably 'strong enough' to explain a large portion of observed open space.

\section{Conclusions}

The results developed here have important implications for the further study of land use. While equilibrium land prices in the static model do reflect the value of open space, equilibrium land prices in the dynamic model and the model with sequential arrival do not. Therefore, hedonic analyses of housing prices which estimate the value of access to open space are reasonable only if the simultaneous arrival game is true. This is a surprising result, and my intuition is that it applies only to those land transactions which set the patterns of development that are to be followed by future development.

The model and results presented here also have important implications for further theoretical analyses. In models where migration is possible, an equilibrium is often defined to occur only when prices have adjusted so that all residents are indifferent between their chosen location and a reservation utility level associated with migration. In the game with sequential arrival and in the dynamic game, we see that this need not be a property of equilibrium. This suggests that this common approach to modeling cities must be used with care if it is to yield useful insights about the implications of landscape preferences.

Preferences for open space naturally give rise to negative landscape externalities, as people do not account for the cost they impose on their neighbors by altering the landscape. The policy response to such externalities is to create open space in densely populated regions of the city at the urban/suburban boundary. This result appears to be robust to general specifications of landscape preferences: If people derive utility from proximity to open space, then landscape externalities will surely arise, and increases in Benthamite welfare measures will surely be larger when open space is created in densely populated rather than in sparsely populated areas. Conversely, a policy of "infilling" vacant locations near the urban/surban boundary will not be welfare improving.

The results presented here also suggest that creating parks in undeveloped areas before they are subject to development pressures will reduce leapfrogging development. Intuitively, this seems reasonable. Such parks could reduce the competition between landlords and hence reduce the incentives for immigrants to locate in remote low density areas.

\footnotetext{
${ }^{15} \mathrm{~A}$ disc of radius $400 \mathrm{~m}$ has an area of $400^{2} \pi \mathrm{m}^{2}=502,660 \mathrm{~m}^{2}$, or 50.3 hectares. There are 2.47 acres per hectare, so that a disc of radius $400 \mathrm{~m}$ has an area of $50.3 \times 2.47=124.24$ hectares. Moving from a neighborhood of zero open space to a neighborhood with $50 \%$ open space requires that the number of acres of open space with $400 \mathrm{~m}$ of the house increase from zero to $124.24 / 2=62.12$ acres. From E. G. Irwin [12], each acre of additional open space increases the a house's value by 1530 dollars, so moving from a neighborhood with no open space to a neighborhood with $50 \%$ open space increases the value of a house by $62.12 \times 1530=95044$ dollars. Converting this to a flow using a $5 \%$ discount rate suggests that the annual value of the flow of open space services is $95044 / 20=4752$ dollars per year.
} 
The results presented here also suggest that policy makers should regard greenbelts with caution. If such green belts are sufficiently durable they have the potential to constrain the shape of the city in a way that is welfare decreasing (absent other features in the economy which might make them desirable). On the other hand, if greenbelts are allowed to migrate outward as the interior fills up to suburban densities, then they can serve to prohibit socially inefficient leapfrog development without constraining the final layout of the city.

More generally, these results suggest that a world with landscape externalities requires a much more active government than economists often consider in this context. Simply imposing congestion taxes and getting property taxes right is not enough. Regulation or taxes which affect the micro-structure of urban landscapes is necessary for an optimal outcome.

\section{References}

[1] J. Geoghegan, The value of open spaces in residential land use, Land Use Policy 19 (1) (2002) 91-98.

[2] M. Burchfield, H. G. Overman, D. Puga and M. A. Turner, Sprawl: A portrait from space, processed, University of Toronto (2003).

[3] American Planning Association, Policy Guide on Smart Growth, ratified by Board of Directors, April 15, 2002, American Planning Association, Chicago, IL, 2002.

[4] American Institute of Architects, Communities by Design, publication W900, American Institute of Architects, New York, 2001.

[5] D. J. O'Neill, Environment and Development: Myth and Fact, ULI - the Urban Land Institute, Washington, DC, 2002.

[6] Sierra Club, Guidelines Adopted by the Transportation Committee, Sierra Club, Washington, DC, 1994.

[7] Trust for Public Land and Land Trust Alliance, Land Vote 2001: Americans Invest in Parks and Open Spaces, Trust for Public Land and Land Trust Alliance, San Francisco, CA, and Washington, DC, 2002.

[8] S. D. Shultz and D. A. King, The use of census data for hedonic price estimates of open-space amenities and land use, Journal of Real Estate Finance and Economics 22 (2/3) (2001) 239-252.

[9] M. Kahn, City quality-of-life dynamics: Measuring the costs of growth, Journal of Real Estate Finance and Economics 22 (2/3) (2001) 339-352.

[10] J. Geoghegan, L. A. Wainger and N. E. Bockstael, Spatial landscape indices in a hedonic framework: an ecological economics analysis using GIS, Ecological Economics 23 (3) (1997) 251-264.

[11] E. G. Irwin and N. E. Bockstael, Interacting agents, spatial externalities and the evolution of residential land use patterns, Journal of Economic Geography 2 (1) (2002) 31-54.

[12] E. G. Irwin, The effects of open space on residential property values, Land Economics 78 (4) (2002) 465-480. 
[13] G. Acharya and L. Lewis Bennett, Valuing open space and land use patterns in urban watersheds, Journal of Real Estate Finance and Economics 2/3 (22) (2001) 221-237.

[14] J. V. Henderson and A. Mitra, The new urban landscape: Developers and edge cities, Regional Science and Urban Economics 26 (6) (1996) 613-643.

[15] M. Fujita and H. Ogawa, Multiple equilibria and structural transition of non-monocentric urban configurations, Regional Science and Urban Economics 12 (2) (1982) 161-196.

[16] R. W. Helsley, Knowledge production in the CBD, Journal of Urban Economics 28 (3) (1990) 391-403.

[17] M. Berliant, S. Peng and P. Wang, Production externalities and urban configuration, Journal of Economic Theory 104 (2) (2002) 275-303.

[18] R. E. Lucas, Jr. and E. Rossi-Hansberg, On the internal structure of cities, Econometrica 70 (4) (2002) 1445-1476.

[19] J. C. Ohls and D. Pines, Discontinuous urban-development and economic efficiency, Land Economics 51 (3) (1975) 224-234.

[20] M. Fujita, Spatial patterns of urban-growth - optimum and market, Journal of Urban Economics 3 (3) (1976) 209-241.

[21] D. E. Mills, Growth, speculation and sprawl in a monocentric city, Journal of Urban Economics 10 (2) (1981) 201-226.

[22] J. K. Brueckner and B. Vonrabenau, Dynamics of land-use for a closed city, Regional Science and Urban Economics 11 (1) (1981) 1-17.

[23] G. K. Turnbull, Residential development in an open city, Regional Science and Urban Economics 18 (2) (1988) 307-320.

[24] R. M. Braid, Residential spatial growth with perfect foresight and multiple income groups, Journal of Urban Economics 30 (3) (1991) 385-407.

[25] R. M. Braid, Optimal spatial growth of employment and residences, Journal of Urban Economics 24 (2) (1988) 227-240.

[26] M. Fujita, Urban spatial dynamics: a review, Sistemi Urbani 3 (1983) 411-475.

[27] A. Bar-Ilan and W. C. Strange, Urban development with lags, Journal of Urban Economics 39 (1) (1996) 87-113.

[28] K. T. Rosen and L. Katz, Growth management and land use controls: The San Francisco bay area experience, American Real Estate and Urban Economics Association Journal 9 (4) (1981) 321-344.

[29] L. Katz and K. T. Rosen, The interjurisdictional effects of growth controls on housing prices, Journal of Law \& Economics 30 (1) (1987) 149-160.

[30] R. Walsh, Analysing open space policies an a locational equilibrium model with endogenous landscape amenities, processed, University of Colorado at Boulder (2002).

[31] L. Tajibaeva, R. Haight and S. Polasky, A discrete space model with environmental amenities, processed, University of Minnesota (2003). 
[32] J. K. Brueckner, Urban sprawl: Lessons from urban economics, Brookings-Wharton Papers on Urban Affairs (2001) 65-97.

[33] W. C. Strange, Overlapping neighborhoods and housing externalities, Journal of Urban Economics 32 (1) (1992) 17-39.

[34] J. J. Wu and A. J. Plantinga, The influence of public open space on urban spatial structure, Journal of Environmental Economics and Management 46 (2) (2003) 288-309.

[35] D. E. Wildasin, Spatial variation of the marginal utility of income and unequal treatment of equals, Journal of Urban Economics 19 (1) (1986) 125-129.

[36] J. K. Brueckner, The economics of urban yard space - an implicit-market model for housing attributes, Journal of Urban Economics 13 (2) (1983) 216-234.

[37] P. Cheshire and S. Sheppard, The welfare economics of land use planning, Journal of Urban Economics 52 (2) (2002) 242-269.

\section{Proofs:}

Theorem 1 Assume that neither $w-u_{\theta}$ nor $w-u_{\theta}+\delta$ are integers and that $n>w-u_{\theta}+\delta$. Then $X_{N}^{*}$ is a Nash equilibrium location profile if and only if the following conditions hold:

1. All locations $y \leq \underline{y}$ are occupied, where $y=\operatorname{int}\left(w-u_{\theta}\right)$.

2. All spaces $y>\bar{y}$ are vacant, where $\bar{y}=\operatorname{int}\left(w-u_{\theta}+\delta\right)$.

3. Alternate spaces are occupied in the region $\{\underline{y}+1, \ldots, \bar{y}\}$, with $\underline{y}+1$ vacant.

Proof: Let $S^{*}$ be an equilibrium and $X^{*}$ an equilibrium outcome.

No location greater than $\bar{y}$ can be occupied in equilibrium. Even if such a location has no neighbors, an immigrant is better off choosing $\theta$. Since $n>\operatorname{int}\left(w-u_{\theta}+\delta\right)=\bar{y}$, it follows that, in equilibrium, some immigrant must choose $\theta$.

Suppose that $y \leq \underline{y}$ is vacant and $S_{i}=\theta$. If $i$ deviates to $y$, then $u_{i}\left(y, 0, X_{-i}\right) \geq w-\underline{y}=$ $w-\operatorname{int}\left(w-u_{\theta}\right)>w-\left(w-u_{\theta}\right)=u_{\theta}$. Therefore, if $X^{*}$ is an equilibrium location profile, (1) holds.

Now suppose that $y>\bar{y}$ is occupied. Since $y$ and $\bar{y}$ are integers, it follows that $y \geq \bar{y}+1$. Thus, $u_{i(y)}\left(y, 0, X_{-i(y)}\right) \leq w-(\bar{y}+1)+\delta=w-\operatorname{int}\left(w-u_{\theta}+\delta\right)-1+\delta<u_{\theta}$. Therefore, if $X^{*}$ is an equilibrium, then (2) holds.

Suppose that $y \in\{\underline{y}+1, \ldots, \bar{y}\}$. Say that $y$ has at least one neighbor and is occupied. Then

$u_{i(y)}\left(y, 0, X_{-i(y)}\right)=w-y \leq w-(\underline{y}+1)<u_{\theta}$. It follows that no occupied space in $\{\underline{y}+1, \ldots, \bar{y}\}$ has a neighbor. Now suppose that $y \in\{\underline{y}+1, \ldots, \bar{y}\}$, is unoccupied, and has no neighbors. If $S_{i}=\theta$, then player $i$ can deviate to location $y$ and get payoff $u_{i}\left(y, X_{-i}\right)=w-y+\delta \geq w-\bar{y}+\delta>u_{\theta}$. It follows that if $X^{*}$ is an equilibrium location profile then every unoccupied location in $\{\underline{y}+1, \ldots, \bar{y}\}$ has at least one occupied neighbor. Now suppose that $y, y+1 \in\{\underline{y}+1, \ldots, \bar{y}\}$ are both unoccupied. We have just shown that $y+2$ must be occupied. But $i(y+2)$ can deviate to $i(y+1)$ and be one unit distance closer to the city center and still not have neighbors. Therefore, $i(y+2)$ should deviate to 
$i(y+1)$. Thus, if $X^{*}$ is an equilibrium location profile then there are no two adjacent vacant spaces in $\{\underline{y}+1, \ldots, \bar{y}\}$. It follows that (3) holds for all equilibrium location profiles.

Now let $X^{*}$ be a location profile satisfying the conditions of the theorem. By construction, all vacant spaces provide a payoff of less than $u_{\theta}$, while all occupied spaces provide a payoff of at least $u_{\theta}$. It follows that no deviation is rational. Hence, $X^{*}$ must be an equilibrium.

Theorem 2 Assume that neither $w-u_{\theta}$ nor $w-u_{\theta}+\delta$ are integers and that $n>w-u_{\theta}+\delta$. A price and location profile $\left(P^{*}, X_{N}^{*}\right)$ is an equilibrium if and only if the following conditions hold:

1. All locations $y \leq y$ are occupied, where $y=\operatorname{int}\left(w-u_{\theta}\right)$.

2. All spaces $y>\bar{y}$ are vacant, where $\bar{y}=\operatorname{int}\left(w-u_{\theta}+\delta\right)$.

3. Alternate spaces are occupied in the region $\{\underline{y}+1, \ldots, \bar{y}\}$.

4.

$$
p_{y}^{*}= \begin{cases}w-u_{\theta}-y & \text { if } y \leq \underline{y} \\ w-u_{\theta}-y+\delta & \text { if } y \in\{\underline{y}+1, \ldots, \bar{y}\} \text { and } y \text { occupied } \\ 0 & \text { if } y \text { vacant. }\end{cases}
$$

Proof: Let $\left(P^{*}, S^{*}\right)$ be an equilibrium strategy profile.

No location greater than $\bar{y}$ can be occupied in equilibrium. Even if such a location has no neighbors and $p_{y}=0$, an immigrant is better off choosing $\theta$. Since $n>\operatorname{int}\left(w-u_{\theta}+\delta\right)=\underline{y}$, it follows that in equilibrium some immigrant must choose $\theta$.

Say $y \leq \underline{y}$ vacant and $S_{i}=\theta$. By hypothesis, the interval $\left(0, w-y-u_{\theta}\right)$ is not empty. Say landlord $y$ chooses $p_{y} \in\left(0, w-y-u_{\theta}\right)$. Then player $i$ 's payoff at $y$ is $u_{i}\left(y, p_{y}, X_{-i}\right) \geq w-y-p_{y}>$ $w-y-\left(w-y-u_{\theta}\right)=u_{\theta}$. It follows that $i^{\prime}$ s best response to landlord $y^{\prime}$ s deviation is to move to $y$. Since $p_{y}>0$ this deviation is also in landlord $y^{\prime}$ s interest. It follows that if $\left(P^{*}, X^{*}\right)$ an equilibrium, then (1) holds.

Say $y>\bar{y}$ is occupied. Since, $y$ and $\bar{y}$ are integers, $y \geq \bar{y}+1$. Thus, $u_{i(y)}\left(y, p_{y}^{*}, X_{-i}^{*}\right)=w-$ $(\bar{y}+1)-p_{y}^{*}+\delta<u_{\theta}-p_{y}^{*} \leq u_{\theta}$. It follows that immigrant $i(y)$ should deviate to $\theta$. Therefore, if $\left(P^{*}, X^{*}\right)$ is an equilibrium, (2) holds.

Suppose $y \in\{\underline{y}+1, \ldots, \bar{y}\}$ and has a neighbor. Then $u_{i(y)}\left(y, p_{y}^{*}, X_{-i}^{*}\right)=w-y-p_{y}^{*} \leq w-y \leq$ $w-(\underline{y}+1)<u_{\theta}$. It follows that no occupied space in $\{\underline{y}+1, \ldots, \bar{y}\}$ has a neighbor in equilibrium. Now say that $y \in\{\underline{y}+1, \ldots, \bar{y}\}$ is unoccupied and has no occupied neighbors, and that $S_{i}=\theta$. Then landlord $y$ can choose $p_{y} \in\left(0, w-y-u_{\theta}+\delta\right)$. If immigrant $i$ deviates to $y$, then his payoff is $u_{i(y)}\left(y, p_{y}, X_{-i}^{*}\right)=w-y-p_{y}+\delta>u_{\theta}$. Since $p_{y}>0$ this deviation is also in the landlord's interest. It follows that, if $\left(P^{*}, X^{*}\right)$ is an equilibrium outcome, then every vacant location in $\{\underline{y}+1, \ldots, \bar{y}\}$ has at least one neighbor, and no occupied location has an occupied neighbor. To complete the proof that (3) is necessary for equilibrium, we now show that no two vacant spaces can be adjacent in $\{\underline{y}+1, \ldots, \bar{y}\}$. Say that $y, y+1 \in\{\underline{y}+1, \ldots, \bar{y}\}$ are vacant. From the above, $y+2$ must be occupied. If landlord $y+1$ offers $p_{y+1} \in\left(0, p_{y+2}+1\right)$ then $i(y+2)$ will deviate to $y+1$ and both landlord $y+1$ and immigrant $i(y+2)$ will be better off. It follows that (3) must hold in any equilibrium outcome. 
If $\left(P^{*}, X^{*}\right)$ is an equilibrium, then all immigrants must be indifferent between their own location, and the most attractive alternative. Otherwise an immigrant could move to make himself better off or a landlord could raise his price without causing his immigrant to move. By assumption occupying an already occupied space entails a large penalty. Hence, the most attractive location is either a vacant space, or $\theta$. In any location profile satisfying conditions (1)-(3) of theorem 2, vacant locations are at best indifferent to $\theta$. It follows that the most attractive action available to immigrants gives payoff $u_{\theta}$. By construction, the price gradient in (4) is such that all immigrants receive payoff $u_{\theta}$. Hence, (4) must hold in equilibrium outcomes.

Let $\left(P^{*}, S^{*}\right)$ be a strategy profile satisfying conditions (1)-(4).

By construction, all immigrants are indifferent between their own location and $\theta$, and $\theta$ is at least as good as any available open space. It follows that no immigrant deviates from $\left(P^{*}, S^{*}\right)$.

Since all immigrants are indifferent between their own location, and $\theta$, if landlord $y$ chooses $p_{y}>p_{y}^{*}$ then immigrant $i(y)$ moves and landlord $y$ receives the opportunity cost of his land. Conversely, if landlord $y$ chooses $p_{y}<p_{y}^{*}$ he decreases his payoff. It follows that $p_{y}$ is a best response to $\left(P_{-y}^{*}, S^{*}\right)$. Thus, no landlord deviates from $\left(P^{*}, S^{*}\right)$, and $\left(P^{*}, S^{*}\right)$ is an equilibrium.

Theorem 3 Assume that $n>w-u_{\theta}+\delta$. Let $\underline{y}=\operatorname{int}\left(w-u_{\theta}\right)$, and let $t$ be the largest integer satisfying $2 t<\delta$. Along any equilibrium path immigrants 1 to $t$ occupy locations $(\underline{y}+2, \underline{y}+4 \ldots, \underline{y}+2 t)$. The remaining immigrants occupy spaces $1, \ldots, \underline{y}$ or $\theta$ in any order.

Equilibrium land prices satisfy:

$$
p_{y}^{*}=\left\{\begin{array}{lll}
w-y-u_{\theta} & \text { if } & y \in\{1, \ldots, \underline{y}\} \\
\min \left(1, w-u_{\theta}+\delta-y\right) & \text { if } & y \in\{\underline{y}+2, \underline{y}+4, \ldots, \underline{y}+2 t\} \\
0 & \text { else. } &
\end{array}\right.
$$

Given location profile $X_{i}$, prices and immigrant strategies $\left(P, S_{N}\right)$, and location choice $y_{i}$, let $\chi\left(y_{i}, X_{i}, P, S_{N}\right)$ be an indicator variable which takes the value 1 if location $y_{i}$ has a neighbor in the final location profile which follows from move $y_{i}$. To improve legibility I usually suppress arguments of $\chi$.

Proof: I first show that any equilibrium location profile must have the form required by the theorem.

(1) For any equilibrium strategies $\left(P^{*}, S^{*}\right)$ there is no node at which an immigrant occupies a position $y>w+\delta-u_{\theta}$. Even if such a space remains without neighbors, an immigrant's utility at such a location is $u(y, \chi=1)=w-y-p_{y}+\delta$. Even if $p_{y}=0$, if $y>w+\delta-u_{\theta}$, then $u(y, \chi=1)<u_{\theta}$. It follows that the immigrant occupying $y$ is better off moving to another city. Thus, for any equilibrium strategies, $\left(P^{*}, S^{*}\right)$, there is no node at which an immigrant occupies a position $y>w+\delta-u_{\theta}$, and hence, for any equilibrium location profile, all $y>w+\delta-u_{\theta}$ are vacant.

(2) For any equilibrium strategies, $\left(P^{*}, S^{*}\right)$, there is no node at which an immigrant occupies a position $y>w-u_{\theta}$ if either $y-1$ or $y+1$ is already occupied. By construction, location $y$ must have a neighbor at the end of play. Hence, the utility associated with position $y$ is $u(y, \chi=0)=$ $w-y-p_{y}$. If $y>w-u_{\theta}$ it follows that $u(y, \chi=0)<u_{\theta}$ for any non-negative $p_{y}$. It follows that 
the immigrant occupying $y$ is better off moving to another city. Thus, if any location in the region $\left[w-u_{\theta}, w-u_{\theta}+\delta\right]$ is occupied, its neighbors must remain vacant.

(3) If $X_{N}$ is the equilibrium location profile associated with strategy profile $\left(P^{*}, S^{*}\right)$, then all $y<w-u_{\theta}$ are occupied. For the sake of contradiction, say $y \notin X_{N}$ and $y<w-u_{\theta}$. It follows that profits for landlord $y$ are zero. Suppose landlord $y$ were to choose $p_{y} \in\left(0, w-u_{\theta}-y\right)$. Let $i$ be the last immigrant to choose a different city. If this player instead chooses $y$, then his payoff is $w-y-p_{y}>u_{\theta}$, so that occupying location $y$ is a best response to landlord $y^{\prime}$ s new price. It follows that choosing $p_{y} \in\left(0, w-u_{\theta}-y\right)$ increases landlord $y^{\prime}$ s profits, and hence, that all $y<w-u_{\theta}$ are occupied in equilibrium.

(4) If $X_{N}$ is an equilibrium outcome, then there is no location in $\left[w-u_{\theta}, w-u_{\theta}+\delta\right]$ that does not have at least one neighbor. For the sake of contradiction, say that $y$ and its neighbors are vacant with $y \in\left[w-u_{\theta}, w-u_{\theta}+\delta\right]$. It follows that landlord $y^{\prime}$ s profits are zero. Suppose this landlord were to choose $p_{y} \in\left(0, w-u_{\theta}+\delta-y\right)$. Let $i$ be the last immigrant to choose $S_{i}=\theta$. If this player changes his move to $y$, then, by (1) he is assured that he will remain without neighbors at the end of the game. Thus, choosing $y$ rather than $\theta$ is a best response to landlord $y^{\prime}$ s new price. Since $p_{y}>0$ it follows that landlord $y$ prefers this price, and hence that a vacant space without neighbors cannot occur in $\left[w-u_{\theta}, w-u_{\theta}+\delta\right]$ in an equilibrium location profile.

(5) Given that no three adjacent vacant spaces occur in $\left[w-u_{\theta}, w-u_{\theta}+\delta\right]$, I next show that no two adjacent spaces can occur in this region in equilibrium. For the sake of contradiction, suppose that $y-1$ and $y$ are vacant. By (4) $y+1$ must be occupied. Suppose that landlord $y$ chooses $p_{y}=p_{y+1}+\frac{1}{2}$. We know from (2) that immigrant $i(y+1)$ does not have neighbors. If immigrant $i(y+1)$ chooses location $y$ over $y+1$, then from (1), we know that this space will also not have neighbors at game's end. Thus, $i(y)$ increases his payoff by $1 / 2$ by choosing $y$ over $y+1$. Since such a change in price increases landlord $y^{\prime}$ s profits from zero to $p_{y}=p_{y+1}+\frac{1}{2}$, we have a contradiction.

(1)-(5) above establish that in any equilibrium location profile must be as described in the theorem. To finish the proof, it remains to characterize equilibrium prices and the order in which locations are occupied.

(6) From (3) we know that all locations $y \leq y$ are occupied in any equilibrium outcome. For the sake of contradiction, suppose that $p_{y}^{*} \neq w-u_{\theta}-y$ for some $y<\underline{y}$. Say that $p_{y}^{*}>w-u_{\theta}-y$ for such a location. In this case, since location $y$ must have neighbors in any equilibrium $i(y)^{\prime} \mathrm{s}$ payoff is strictly less than $u_{\theta}$ and he is better off deviating to $\theta$. Thus, $p_{y}^{*}>w-u_{\theta}-y$ is not an equilibrium for $y<\underline{y}$. Say that $p_{y}^{*}<w-u_{\theta}-y$ for some $y<\underline{y}$. In this case, if landlord $y$ deviates to $p_{y}^{\prime}=p_{y}^{*}+\frac{1}{2}\left(w-y-u_{\theta}-p_{y}^{*}\right)$ player $i(y)^{\prime}$ s payoff is still greater than $u_{\theta}$. Thus, either $i(y)$ stays at location $y$ or some other immigrant deviates from $\theta$ to locate at $y$. Thus, the only possible equilibrium price is $p_{y}^{*}=w-u_{\theta}-y$ for $y \leq \underline{y}$.

(7) Suppose immigrant 1 occupies location $\underline{y}+1$. Then, by (3) we know that this location will have a neighbor and by construction $\underline{y}+1>w-u_{\theta}$. It follows that immigrant 1 is better off playing $\theta$. Now suppose immigrant 1 occupies $y^{\prime}>y+2$. By (3), such a choice implies that location $y^{\prime}-1$ remains empty, so that landlord $y^{\prime}-1$ should choose $p_{y^{\prime}-1} \in\left(0, p_{y^{\prime}}+1\right)$. In this case, immigrant 1 will deviate to location $y^{\prime}-1$. Thus, immigrant 1 can only occupy $\underline{y}+2$ or $y \leq \underline{y}$ 
in any equilibrium.

Now suppose that landlord $\underline{y}+2$ chooses $p_{\underline{y}+2}>1$. In this case, if immigrant 1 occupies $\underline{y}+2$, landlord $\underline{y}+3$ should offer a low price $p_{y+3} \in\left(0, \max \left\{p_{\underline{y}+2}-1,1\right\}\right)$ and player 1 should deviate. Thus, $p_{y+2}>1$. On the other hand, as long as $p_{y+2} \leq 1$ there is no non-negative price at which immigrant 1 will deviate from $y+2$ to $y+3$. Thus, landlord $y+2$ chooses $p_{y+2}=1$ in equilibrium. It follows that immigrant 1 occupies location $\underline{y}+2$ at price $p_{\underline{y}+2}=1$.

Similar logic establishes that immigrant 2 occupies location $\underline{y}+4$ at price 1 , and so on. Immigrant $t$ however, will occupy the last suburban location, and if $w-(\underline{y}+2 t)+\delta<1$, then $p_{\underline{y}+2 t}=w-(\underline{y}+2 t)+\delta$. After all suburban locations are occupied, subsequent immigrants occupy location in $\{1, \ldots, y\}$. By (6) these locations all result in reservation utility level so they are occupied in any order.

Theorem 4 Suppose that $w-y-\delta$ and $w-y+\delta$ are not integers and that $n>w-u_{\theta}+\delta$. Then there is a unique optimal location profile, $X^{* *}$, and this profile satisfies the following three conditions:

1. All $y \leq \underline{y}^{* *}$ are occupied, where $\underline{y}^{* *}=\operatorname{int}\left(w-u_{\theta}-\delta\right)$.

2. All $y>\bar{y}$ are vacant, where $\bar{y}=\operatorname{int}\left(w-u_{\theta}+\delta\right)$.

3. Alternate locations are occupied in the set $\left\{\underline{y}^{* *}, \ldots, \bar{y}\right\}$.

Proof: Suppose $X^{* *}$ does not satisfy at least one of conditions (1) - (3).

If $X^{* *}$ does not satisfy condition (1), then there is some smallest vacant $y^{\prime}<\underline{y}^{* *}$. If some immigrant $i$ moves from $\theta$ to $y^{\prime}$, then at most one immigrant, $y^{\prime}+1$, is deprived of open space benefits. Thus, the change in $W$ associated with $i^{\prime}$ s move to $y^{\prime}$ is at least $w-y^{\prime}-u_{\theta}-\delta$. Since $y^{\prime}<y^{* *}$ by hypothesis, this change is positive. Thus, $X^{* *}$ cannot be an optimal location profile if condition (1) is not satisfied.

If $X^{* *}$ does not satisfy condition (2), then there is some largest occupied $y^{\prime}>\bar{y}$. Even if immigrant $i\left(y^{\prime}\right)$ has no neighbors in $X^{* *}$, his move to $\theta$ results in a change in welfare of $-\left(w-y^{\prime}+\delta-u_{\theta}\right)$. By hypothesis, $y^{\prime}>\bar{y}$, so this quantity is positive. It follows that if $X^{* *}$ does not satisfy condition (2) it is not optimal.

If $X^{* *}$ does not satisfy condition (3), then the region $\left\{y^{* *}, \ldots, \bar{y}\right\}$ either contains two adjacent occupied spaces, or two adjacent vacant spaces. First consider the case when there are adjacent occupied spaces. Say $y^{\prime}$ and $y^{\prime}+1$ are the two most extreme adjacent occupied spaces. If $i\left(y^{\prime}\right)$ moves to $\theta$, then $i\left(y^{\prime}+1\right)^{\prime}$ s payoff increases by $\delta$ since he now has open spaces on either side. Tenant $i\left(y^{\prime}\right)^{\prime}$ s payoff also increases since $w-y^{\prime}<u_{\theta}$. Thus, if there are two adjacent occupied spaces in $\left\{\underline{y}^{* *}, \ldots, \bar{y}\right\}$, then $X^{* *}$ is not optimal.

Now suppose that there are two adjacent vacant spaces in $\left\{\underline{y}^{* *}, \ldots, \bar{y}\right\}$, and let $y^{\prime}$ and $y^{\prime}+1$ denote the two most extreme such spaces. Suppose that there is at least one occupied location more extreme that $y^{\prime}+1$, and that $y^{\prime \prime}$ is the least extreme of these locations. If $i\left(y^{\prime \prime}\right)$ moves from $y^{\prime \prime}$ to $y^{\prime}+1$ then he decreases his commuting costs by $y^{\prime \prime}-\left(y^{\prime}+1\right)$, does not forego his own open space benefit, and does not cause anyone else to lose their open space benefit. Finally, suppose that there are two adjacent open spaces in $\left\{\underline{y}^{* *}, \ldots, \bar{y}\right\}$ and there is no more remote occupied location. In 
this case, some immigrant who chose $\theta$ can choose $y^{\prime}+1$ and get a payoff $w-\left(y^{\prime}+1\right)+\delta>u_{\theta}$. It follows that any optimal location profile must satisfy condition (3).

We now show that any location profile satisfying (1)-(3) is optimal.

First note that $W(X)$ is bounded above and below. A lower bound of $W(X)$ is obtained if we suppose that every immigrant receives the payoff associated with occupying the most extreme location in $Y$ and having a neighbor. An upper bound of $W(X)$ is obtained if we suppose that every immigrant in $N$ receives the payoff associated with location 1 and not having a neighbor. Since both $N$ and $Y$ are finite, it follows that $W(X)$ is bounded above and below. Second, since $Y$ is a finite set by assumption, there are a finite number of possible location profiles. It follows that the set $\{W(X)\}_{X \subset Y}$ is a finite bounded subset of the real numbers. It follows immediately that $\{W(X)\}_{X \subset Y}$ has a largest element, and hence that there exists a non-empty set of optimal location profiles.

Since we know that the set of optimal location profiles is non-empty, and that each must satisfy conditions (1)-(3), if there is a unique location profile satisfying (1)-(3) if follows that such a profile must be optimal. By inspection of conditions (1)-(3) it is clear that there is exactly one location profile satisfying the conditions. It follows that this profile must be the unique optimal location profile.

Theorem 5 Let $\bar{y}=\operatorname{int}\left(w-(1-\gamma) u_{\theta}+\delta\right)$ and $\underline{y}=\operatorname{int}\left(w-(1-\gamma) u_{\theta}\right)$. If $n>\bar{y}$ then any equilibrium of the dynamic game satisfies:

1. In any equilibrium location profile $X_{N}^{*}$ all spaces $y>\bar{y}$ are vacant.

2. In any equilibrium location profile $X_{N}^{*}$ all locations $y \leq y$ are occupied, and they are occupied before any immigrant chooses $\theta$.

3. Before any immigrant chooses $\theta$ alternate spaces are occupied in the region $\{\underline{y}+1, \ldots, \bar{y}\}$, with $\underline{y}+2$ occupied first and progressively more extreme alternate locations occupied in sequence.

Proof: An immigrant occupying an arbitrary space can achieve no greater payoff than $\frac{1}{1-\gamma}(w-$ $y+\delta)$, which occurs only in the event that $p_{y}=0$ and the location is without neighbors in perpetuity. If an immigrant occupies a location $y^{\prime}>\bar{y}$, then $U_{i}\left(y^{\prime}, k\right) \leq \frac{1}{1-\gamma}(w-(\bar{y}+1)+\delta)$. From the definition of $\bar{y}$, it follows immediately that $U_{i}\left(y^{\prime}, k\right)<u_{\theta}$. Therefore, there is no node such that $S_{i}^{*}>\bar{y}$. It follows immediately that condition (1) must hold in equilibrium.

By (1), we know that there is no node such that a location greater than $\bar{y}$ is ever occupied in equilibrium. Since $n>\bar{y}$ by hypothesis, it follows that some immigrant chooses $\theta$.

Let $y^{\prime}$ be the least extreme vacant location in $X_{i}$. Since location 0 is occupied, $y^{\prime}$ must have at least one neighbor. It follows that no immigrant will ever pay more that $w-y-u_{\theta}$ to occupy $y^{\prime}$. For the sake of contradiction, suppose immigrant $i$ chooses $\theta$ when $y \leq y$ is vacant. Then $U_{i}=u_{\theta}$ and the largest possible payoff for landlord $y^{\prime}$ is $\Pi_{y^{\prime}}=\gamma^{i+1}\left(w-y-u_{\theta}\right)$. If landlord $y^{\prime}$ chooses $p_{y^{\prime}}^{i} \in\left(\gamma\left(w-y-u_{\theta}\right),\left(w-y-u_{\theta}\right)\right)$, then immigrant $i$ can occupy location $y^{\prime}$ for a payoff strictly larger than $u_{\theta}$. Moreover, by construction, $\gamma^{i} p_{y^{\prime}}^{i}>\gamma^{i+1}\left(w-y-u_{\theta}\right)$. It follows that there is no node at which immigrant $i$ chooses $\theta$ when $y \leq \underline{y}$ is vacant. Since $n>\underline{y}$ by hypothesis, condition (2) follows. 
The proof of condition (3) is in three parts. (A) In equilibrium there is no node such that a location $y^{\prime} \in\{\underline{y}+2, \ldots, \bar{y}\}$ is occupied when $y^{\prime}-1$ and $y^{\prime}-2$ are also vacant. This implies that suburban locations are occupied in order from $y$ to $\bar{y}$, and that there is at most one vacant space between occupied locations. (B) In equilibrium there is no node such that a location in $\{\underline{y}+1, \ldots, \bar{y}\}$ with a neighbor is ever occupied. Together with (A), this implies that there is at least one vacant space between occupied locations. (C) There is no node at which an immigrant chooses $\theta$ if there are three adjacent vacant locations in $\{\underline{y}+2, \ldots, \bar{y}\}$. With $(\mathrm{A})$ and $(\mathrm{B})$, this implies that alternate spaces throughout the suburbs are occupied before immigrants begin choosing $\theta$. Together, these conditions assure that condition (3) holds.

Begin with (B). Let $\left(S_{Y}^{*}, S_{N}^{*}\right)$ be an equilibrium. Then there is no node such that $S_{i}^{*}=y^{\prime}$ when $y^{\prime}>y$ and $y^{\prime}-1$ or $y^{\prime}+1$ is occupied. Say location $y^{\prime}-1$ is occupied and $y^{\prime}>y$. Then immigrant $i^{\prime}$ s utility at location $y^{\prime}$ is:

$$
\begin{aligned}
U_{i}\left(y^{\prime}, 0\right) & =\frac{1}{1-\gamma}\left(w-y^{\prime}\right)-p_{y}^{\prime} \\
& <\frac{1}{1-\gamma}\left(w-\left(w-(1-\gamma) u_{\theta}\right)\right)-p_{y}^{\prime} \\
& \leq u_{\theta} .
\end{aligned}
$$

Therefore, $S_{i}^{*}=y^{\prime}$ is not a best response. $S_{i}=\theta$ gives immigrant $i$ a strictly higher payoff.

(A) Let $\left(S_{Y}^{*}, S_{N}^{*}\right)$ be an equilibrium. Then there is no node such that $S_{i}^{*}=y^{\prime}$ when $y^{\prime}>\underline{y}+1$ and $y^{\prime}-1$ and $y^{\prime}-2$ are vacant. Let $\left(S_{Y}^{*}, S_{N}^{*}\right)$ be an equilibrium. Say $S_{i}^{*}=y^{\prime}$ when $y^{\prime}>\underline{y}+1$ and $y^{\prime}-1$ and $y^{\prime}-2$ are vacant. By (B), if $y^{\prime}$ is occupied then location $y^{\prime}-1$ cannot be occupied and landlord $y^{\prime}-1^{\prime}$ s payoff is zero. Since $p_{y^{\prime}} \geq 0$ the interval $\left(0, p_{y^{\prime}}+\frac{1}{1-\gamma}\right)$ is non-empty. Suppose landlord $y^{\prime}-1$ chooses $p_{y^{\prime}-1} \in\left(0, p_{y^{\prime}}+\frac{1}{1-\gamma}\right)$ and immigrant $i$ deviates from $S_{i}^{*}=y^{\prime}$ to $y^{\prime}-1$. By (B) immigrant $i$ is assured that he will never have neighbors. Therefore,

$$
\begin{aligned}
U_{i}\left(y^{\prime}-1, \infty\right) & =\frac{1}{1-\gamma}\left(w-\left(y^{\prime}-1\right)+\delta\right)-p_{y^{\prime}-1} \\
& =\frac{1}{1-\gamma}(w-y+\delta)-p_{y^{\prime}-1}+\frac{1}{1-\gamma} \\
& >\frac{1}{1-\gamma}(w-y+\delta)-\left(p_{y^{\prime}}+\frac{1}{1-\gamma}\right)+\frac{1}{1-\gamma} \\
& =\frac{1}{1-\gamma}(w-y+\delta)-p_{y^{\prime}} \\
& =U_{i}\left(y^{\prime}, \infty\right) .
\end{aligned}
$$

Therefore this deviation is in immigrant $i$ 's interest. Since it results in a positive rather than a zero payoff for landlord $y^{\prime}-1$, it is also in this landlord's interest. Condition (A) follows.

(C) There is no node at which an immigrant chooses $\theta$ if there are three adjacent vacant locations in $\{\underline{y}, \ldots, \bar{y}\}$. Say $y^{\prime}-1, y^{\prime}, y^{\prime}+1 \in\{\underline{y}, \ldots, \bar{y}\}$ are vacant and immigrant $i$ chooses $\theta$. The most that any immigrant will pay to locate at $y^{\prime}$ is $\frac{1}{(1-\gamma)}\left(w-y^{\prime}+\delta\right)-u_{\theta}$. If immigrant $i$ chooses $\theta$ the highest payoff possible for landlord $y^{\prime}$ is $\Pi_{y^{\prime}}=\gamma^{i+1}\left(\frac{1}{(1-\gamma)}\left(w-y^{\prime}+\delta\right)-u_{\theta}\right)$. Suppose that landlord $y^{\prime}$ chooses $p_{y^{\prime}}^{i} \in\left(\gamma\left(\frac{1}{(1-\gamma)}\left(w-y^{\prime}+\delta\right)-u_{\theta}\right),\left(\frac{1}{(1-\gamma)}\left(w-y^{\prime}+\delta\right)-u_{\theta}\right)\right)$. Since $\gamma<1$ this interval is not empty. If accepted in period $i$, any such price gives the landlord a higher payoff than is possible 
otherwise. If immigrant $i$ deviates from $\theta$ to $y^{\prime}$, then by (B) he will have no neighbors in perpetuity and his utility is:

$$
\begin{aligned}
U_{i}\left(y^{\prime}, \infty\right) & =\frac{1}{1-\gamma}\left(w-\left(y^{\prime}-1\right)+\delta\right)-p_{y} \\
& >\frac{1}{1-\gamma}\left(w-y^{\prime}+\delta\right)-\left(\frac{1}{1-\gamma}\left(w-y^{\prime}+\delta\right)-u_{\theta}\right) \\
& >u_{\theta} .
\end{aligned}
$$

Therefore, this deviation is in the interest of landlord $y^{\prime}$ and immigrant $i$. Condition (C) follows.

Theorem 6 Let $\bar{y}=\operatorname{int}\left(w-(1-\gamma) u_{\theta}+\delta\right)$ and $\underline{y}=\operatorname{int}\left(w-(1-\gamma) u_{\theta}\right)$. If $n>\bar{y}$, then in any equilibrium of the dynamic game, if immigrant $i$ chooses location $y \in\{\underline{y}, \ldots, \bar{y}\}$ then $p_{y}^{i} \leq \frac{1}{1-\gamma}$.

Proof: For the sake of contradiction, say that $p_{y}^{i}>\frac{1}{1-\gamma}$ and immigrant $i$ occupies $y$ for some $y \in\{\underline{y}, \ldots, \bar{y}\}$. By the same logic used in the proof of (3)(B) of theorem 5, immigrant $i$ has no neighbors in perpetuity. Thus,

$$
U_{i}(y, \infty)=\frac{1}{1-\gamma}(w-y+\delta)-p_{y}^{i}
$$

and landlord $y+1$ is assured of a zero payoff.

Say landlord $y+1$ chooses $p_{y+1}^{i} \in\left(0, p_{y}^{i}-\frac{1}{1-\gamma}\right)$. Since $p_{y}^{i}>\frac{1}{1-\gamma}$ by hypothesis, this interval is not empty. If immigrant $i$ deviates to $y+1$ then, by the logic used in the proof of theorem 5 (3)(b) and recalling that more remote suburban locations are occupied later, this location too has no neighbors in perpetuity. Thus,

$$
\begin{aligned}
U_{i}(y-1, \infty) & =\frac{1}{1-\gamma}(w-(y+1)+\delta)-p_{y-1}^{i} \\
& >\frac{1}{1-\gamma}(w-(y+1)+\delta)-\left(p_{y}^{i}-\frac{1}{1-\gamma}\right) \\
& =\frac{1}{1-\gamma}(w-y+\delta)-p_{y}^{i} \\
& >U_{i}(y, \infty) .
\end{aligned}
$$

Therefore, $p_{y}^{i}>\frac{1}{1-\gamma}$ is not an equilibrium.

Theorem 7 Let $\underline{y}=\operatorname{int}\left(w-(1-\gamma) u_{\theta}\right)$ and $l \in\{0, \ldots, \underline{y}\}$ an integer. Suppose $n>w-(1-\gamma) u_{\theta}+\delta$ and $\delta>\frac{l}{\gamma^{n}}$. Then, in any equilibrium, all $y \in\{\underline{y}-l, \ldots, \underline{y}\}$ are occupied after the first suburban location, $\underline{y}+2$, is occupied.

Proof: For any equilibrium, the proof establishes an upper bound on immigrant payoffs from locating at $y \in\{\underline{y}-l, \ldots, \underline{y}\}$, and a lower bound on immigrant payoffs at $\underline{y}+2$. It then shows that the upper bound of immigrant payoffs at $y \in\{\underline{y}-l, \ldots, \underline{y}\}$ is less than the lower bound from locating at $\underline{y}+2$. The result then follows immediately.

If immigrant $i$ locates at $y \leq \underline{y}$ then his payoff can be no larger than would occur if landlord $y$ accepted a zero price, and location $y$ remained without neighbors until period $n$. Thus, in any 
equilibrium

$$
U_{i}\left(y, k_{N}\right) \leq \frac{1}{1-\gamma}\left(w-y+\left(1-\gamma^{n-i}\right) \delta\right)
$$

From theorem 6 , we know that $p_{y+2}^{i}$ can be no larger than $\frac{1}{1-\gamma}$ if $S_{i}=\underline{y}+2$. From the proof of theorem 5, we know that for any equilibrium, if $i$ locates at $\underline{y}+2$ then he has no neighbors in perpetuity. Thus, if immigrant $i$ locates at $\underline{y}+2$,

$$
U_{i}\left(\underline{y}+2, k_{N}\right) \geq \frac{1}{1-\gamma}(w-(\underline{y}+2)+\delta)-\frac{1}{1-\gamma} .
$$

Immigrant $i$ will choose $y$ before $y+2$ only if

$$
U_{i}\left(y, k_{N}\right) \geq U_{i}(\underline{y}+2, \infty)
$$

Using equation 6 and 7, we see that this can occur only if

$$
\frac{1}{1-\gamma}\left(w-y+\left(1-\gamma^{n-i}\right) \delta\right) \geq \frac{1}{1-\gamma}(w-(\underline{y}+2)+\delta)-\frac{1}{1-\gamma} .
$$

Rearranging, we have

$$
\gamma^{n-i} \delta \leq \underline{y}-y
$$

Since $l \geq y-y$ by hypothesis, and $\gamma^{n-i} \delta \geq \gamma^{n} \delta$, it follows that Equation 8 holds under the hypothesized condition, $\delta>\frac{l}{\gamma^{n}}$. The result follows immediately.

Theorem 8 Let $\underline{y}^{* *}=\operatorname{int}\left(w-(1-\gamma) u_{\theta}-\delta\right)$. If $\left(X_{i}^{* *}\right)_{i \in\{1, \ldots, n, N\}}$ is an optimal sequence of location profiles and $\delta>1$, then for all $i$ no two adjacent locations more extreme than $\underline{y}^{* *}$ are occupied in $X_{i}^{* *}$.

Proof: Say $y^{\prime}$ and $y^{\prime}+1>\underline{y}^{* *}$ are the most extreme pair of adjacent occupied locations in $X_{i}^{* *}$. Let $X_{i}^{\prime}=X_{i}^{* *} / y^{\prime}$. Then

$$
W\left(X_{i}^{\prime}\right)=W\left(X_{i}^{* *}\right)-\left(w-y^{\prime}-(1-\gamma) u_{\theta}\right)+\delta
$$

That is, $W\left(X_{i}^{\prime}\right)$ is equal to $W\left(X_{i}^{* *}\right)$ plus the difference in the surplus generated by locations $y^{\prime}$ and $y^{\prime}+1$ when immigrant $i\left(y^{\prime}\right)$ moves to the alternate city. Rearranging gives,

$$
\left.W\left(X_{i}^{\prime}\right)-W\left(X_{i}^{* *}\right)=y^{\prime}-\left(w-\delta-(1-\gamma) u_{\theta}\right)\right) .
$$

By hypothesis, $y^{\prime} \geq \operatorname{int}\left(w-\delta-(1-\gamma) u_{\theta}\right)+1$, so

$$
\begin{aligned}
W\left(X_{i}^{\prime}\right)-W\left(X_{i}^{* *}\right) \geq & {\left[\operatorname{int}\left(w-\delta-(1-\gamma) u_{\theta}\right)+1\right] } \\
& -\left[w-\delta-(1-\gamma) u_{\theta}\right] \\
> & 0
\end{aligned}
$$


Theorem 9 Let $X_{N}^{* *}$ be a socially optimal location profile. Let $y$ and $y^{\prime}$ be two occupied locations in this profile such that $y^{\prime}>y$, and, neither $y$ nor $y^{\prime}$ has neighbors. Then $y$ is occupied before $y^{\prime}$.

Proof: By contradiction. Say $\left(X_{i}^{* *}\right)_{i \in\{1, \ldots, n, N\}}$ is optimal, with $y^{\prime}>y$ in $X_{N}^{* *}$, neither $y$ nor $y^{\prime}$ has neighbors, and $y$ is occupied before $y^{\prime}$. Let $\left(X_{i}^{\prime}\right)_{i \in\{1, \ldots, n, N\}}$ be identical to $\left(X_{i}^{* *}\right)_{i \in\{1, \ldots, n, N\}}$ except that the order in which $y$ and $y^{\prime}$ are occupied is reversed, thus $i^{\prime}(y)=i^{* *}\left(y^{\prime}\right)$ and $i^{\prime}\left(y^{\prime}\right)=i^{* *}(y)$ so that $y^{\prime}$ is occupied before $y$ in $\left(X_{i}^{* *}\right)_{i \in\{1, \ldots, n, N\}}$. Then,

$$
\begin{aligned}
W^{N}\left(\left(X_{i}^{\prime}\right)_{i \in\{1, \ldots, n, N\}}\right)= & W^{N}\left(\left(X_{i}^{* *}\right)_{i \in\{1, \ldots, n, N\}}\right) \\
& \left.-\Sigma_{j=i^{* *}(y)}^{i^{* *}\left(y^{\prime}\right)} \gamma^{j}\left(w-y^{\prime}-(1-\gamma) u_{\theta}\right)+\delta\right) \\
& \left.+\Sigma_{j=i^{* *}(y)}^{i^{* *}\left(y^{\prime}\right)} \gamma^{j}\left(w-y-(1-\gamma) u_{\theta}\right)+\delta\right) .
\end{aligned}
$$

Since $y<y^{\prime}$, it follows that $W^{N}\left(\left(X_{i}^{\prime}\right)_{i \in\{1, \ldots, n, N\}}\right)>W^{N}\left(\left(X_{i}^{* *}\right)_{i \in\{1, \ldots, n, N\}}\right)$, a contradiction. 